\title{
Review Article \\ Role of Gap Junctions and Hemichannels in Parasitic Infections
}

\author{
José Luis Vega, ${ }^{1,2}$ Mario Subiabre, ${ }^{2}$ Felipe Figueroa, ${ }^{3}$ Kurt Alex Schalper, ${ }^{4}$ Luis Osorio, ${ }^{5}$ \\ Jorge González, ${ }^{5}$ and Juan Carlos Sáez ${ }^{1}$ \\ ${ }^{1}$ Departamento de Fisiología, Pontificia Universidad Católica de Chile, 8330025 Santiago, Chile \\ ${ }^{2}$ Laboratorio de Fisiología Experimental (EPhyL), Instituto Antofagasta (IA), Universidad de Antofagasta, \\ 1270300 Antofagasta, Chile \\ ${ }^{3}$ Inmunología, Departamento de Tecnología Médica, Universidad de Antofagasta, 1270300 Antofagasta, Chile \\ ${ }^{4}$ Department of Pathology, Yale School of Medicine, New Haven, CT 06520-8023, USA \\ ${ }^{5}$ Unidad de Parasitología Molecular, Facultad Ciencias de la Salud, Universidad de Antofagasta, 1270300 Antofagasta, Chile \\ Correspondence should be addressed to José Luis Vega; juvega@uc.cl
}

Received 21 May 2013; Revised 7 August 2013; Accepted 26 August 2013

Academic Editor: Christophe Duranton

Copyright (C) 2013 José Luis Vega et al. This is an open access article distributed under the Creative Commons Attribution License, which permits unrestricted use, distribution, and reproduction in any medium, provided the original work is properly cited.

In vertebrates, connexins (Cxs) and pannexins (Panxs) are proteins that form gap junction channels and/or hemichannels located at cell-cell interfaces and cell surface, respectively. Similar channel types are formed by innexins in invertebrate cells. These channels serve as pathways for cellular communication that coordinate diverse physiologic processes. However, it is known that many acquired and inherited diseases deregulate $\mathrm{Cx}$ and/or Panx channels, condition that frequently worsens the pathological state of vertebrates. Recent evidences suggest that $\mathrm{Cx}$ and/or Panx hemichannels play a relevant role in bacterial and viral infections. Nonetheless, little is known about the role of $\mathrm{Cx}$ - and Panx-based channels in parasitic infections of vertebrates. In this review, available data on changes in $\mathrm{Cx}$ and gap junction channel changes induced by parasitic infections are summarized. Additionally, we describe recent findings that suggest possible roles of hemichannels in parasitic infections. Finally, the possibility of new therapeutic designs based on hemichannel blokers is presented.

\section{Introduction}

Members of gap junction (GJ) familiy proteins form intercellular communication channels, which connect the cytoplasm of neighboring cells and hemichannels, which connect the intra- and extracellular milieu [1]. Both intercellular channels and hemichannels participate in physiologic and pathologic processes including electrical conduction [2], inflammation [3], immune system activation [4], tissue repair/remodeling $[5]$, and response to bacterial $[6,7]$ and viral infections [8]. However, little is known about the role of GJ channels in parasite infection and studies on the possible role of hemichannels are not available. Herein, we summarize the available data on the role of GJ channels in parasitic diseases and we also present new data suggesting that hemichannels might serve as key paracrine communication pathway during parasitic infections.

\section{Gap Junction Channels and Hemichannels}

Connexins (Cxs) and pannexins (Panxs) are members of two different GJ protein families in vertebrates [1]. Both protein subtypes can form channels that serve as pathways of cellular communication $[1,9]$. Cxs and Panxs show similar membrane topology but only modest sequence homology [1]. In rodents and humans Cxs are encoded by 20 and 21 genes, respectively [10], whereas Panxs include only three members [11]. Moreover, innexins (Inxs) are members of a GJ family expressed only in invertebrates (Figure 1) [12]. They show similar membrane topology with Cxs and Panxs and can also form intercellular channels and hemichannels [13]. Inxs were originally identified in Drosophila melanogaster and Caenorhabditis elegans; however, Inx genes have been cloned recently from several other invertebrates (reviewed in [13]). 
Gap junction plaques are clusters of intercellular channels each one formed by head-to-head docking of two hemichannels (Figure 1) [1]. One hemichannel may dock with another one of identical Cx composition (of the adjacent cell) to form a homotypic gap junction channel or with hemichannels containing different $\mathrm{Cx}$ types or $\mathrm{Cx}$ composition to form a heterotypic gap junction channel [14]. The latter, provide a direct pathway for diffusional transfer of ions, metabolites and signaling molecules between adjacent cells $[1,9]$. These channels are essential in several physiological tissue functions such as cardiomyocyte electrical conduction [2], development and regeneration of skeletal muscle [15], endocrine gland secretion [16], and ovarian folliculogenesis [17]. They are also implicated in pathophysiological conditions including hereditary deafness [18], cataract [19], ectodermal dysplasias [20], tumorigenesis [21], and inflammatory responses [3]. For comprehensive description of some of the aforementioned processes, we refer the readers to several recent reviews [22-25].

Hemichannels serve as autocrine/paracrine cellular communication pathways (Figure 1) $[1,26,27]$. They are permeable to ions and small molecules including cytosolic signals. For example, hemichannels formed by Cxs and Panxs are permeable to adenosine triphosphate (ATP). In addition, $\mathrm{Cx}$ hemichannels are permeable to nicotinamide adenine dinucleotide $\left(\mathrm{NAD}^{+}\right)$, glutamate, and prostaglandins $[26,27]$. Recently, several studies have shown the relevance of hemichannels in physiological and pathophysiological conditions. The former include cell volume regulation [28], vascular tone [29], $\mathrm{T}$ cell activation [4], inflammasome activation [30], proliferation of fibroblasts [31] and neuronal progenitors of the retina [32], ischemic preconditioning of cardiomyocytes [33], ischemic tolerance of neurons [34], neuroglial paracrine interactions [35], and potentiation of skeletal muscle contraction [36]. Among pathological conditions, increased opening of astroglial hemichannels potentiates glutamate-induced neurotoxicity by proinflammatory cytokines [37, 38] and $\mathrm{A} \beta$ peptide [39]. In the heart, increased hemichannel activity promotes myocardial damage induced by ischemia [40-43]. For more details about hemichannels, see recent reviews [27, 44-47].

\section{Effects of Parasite Infections on Gap Junction Proteins}

Parasitic infections are a global public health problem in most countries of Asia, Africa, and Latin America, affecting millions of people [48]. Although parasitic diseases have traditionally impacted restricted areas clustered to less economically developed societies and tropical geographic locations, they have gained more attention due to increasing international travels, wide expansion of immune suppressed patients (e.g., HIV-infection, transplant patients, and anticancer treatments), or influx of immigrants from endemic zone to developed countries [48]. Despite the marked increase in their clinical relevance, no vaccines are available for primary prevention and current chemotherapy is associated with considerable toxicity and side effects [48].
Most studies describing the participation of the $\mathrm{Cx}$ formed gap junctions in parasite infections are related to protozoan parasites such Trypanosoma cruzi (T. cruzi) or Toxoplasma gondii (T. gondii, Table 1) [49-55]. Although some studies describe the presence of gap junction channels in parasitic flatworms, the functional significance remains to be elucidated [56-59].

3.1. Trypanosoma cruzi. T. cruzi is the causative agent of Chagas disease that affects about 18 million people in America [60]. The chronic disease causes colopathy, severe arrhythmia, and other electrical heart defects [49-51]. Pioneering studies demonstrated that infection with Tulahuen strain of $T$. cruzi reduces GJ mediated communication in cultured neonatal rat cardiomyocytes [51]. In these cells, Trypanosoma infection reduced both junctional conductance and intercellular transfer of the fluorescent dye Lucifer yellow (LY) [51]. Also, levels of Cx43 were significantly reduced at junctional membrane regions [50, 51]. In cultured mouse myocytes, the infection with the Y strain of T. cruzi increased Cx43 protein levels at one hour after infection, whereas Cx43 transcripts were unaltered. However, analysis at 2472 hours post infection showed a decrease in both $\mathrm{Cx} 43$ protein $(61 \%)$ and mRNA (20\%) levels in both cultured cells and myocardium of infected mice $(\sim 26 \%$ reduction of $\mathrm{Cx} 43$ protein) [49]. Interestingly, cells with pronounced decrease in $\mathrm{Cx} 43$ protein levels showed more abundant intracellular amastigotes, suggesting a direct relationship between host cell parasitism and $\mathrm{Cx} 43$ downregulation in vitro [49]. In astrocytes and leptomeningeal cell cultures, the infection with Tulahuen strain of $T$. cruzi reduced dye coupling between cells, without changes in expression and phosphorylation state of $\mathrm{Cx} 43$ [50]. This effect was associated with reduced Cx43 levels in astrocytes and reduced Cx43 and Cx26 levels in leptomeningeal cells [50]. The authors suggested that impaired intercellular communication resulted from altered targeting of $\mathrm{Cx}$ protein to the plasma membrane and/or changes in assembly of hemichannels [50].

Examination of whole brain samples from mice infected with Brazil strain showed reduced $\mathrm{Cx} 43$ immunostaining [50]. In addition, mice infected with $\mathrm{Y}$ or Brazil T. cruzi strains showed a reduction in $\mathrm{Cx} 43$ levels in atria and ventricle after 11 or 30 days after infection, respectively [49]. Gene profiling of T. cruzi-infected cardiomyocytes revealed suppression of GJA1 and GJC1 genes, which encode for Cx43 and Cx45 proteins, respectively, at 48 hours after infection [61]. Upregulation of GJA4 gene encoding Cx37, a major endothelial cell $\mathrm{Cx}$ was also described [62]. Also, samples from chagasic patients showed alterations of GJs in the heart [54]. Immunohistochemical analysis of left ventricle biopsies from subjects with chronic chagasic disease showed reduction in both mean number $(\sim 20 \%)$ and size ( 2.2 fold $)$ of $\mathrm{Cx} 43$ plaques [54]. The mechanism of $\mathrm{Cx} 43$ reduction after T. cruzi infection is not completely elucidated. However, the participation of CC-chemokines and cytokines such as TGF$\beta$ and TNF- $\alpha$ signaling and perforin-dependent cytolytic mechanisms have been reported [52-55]. In cardiomyocytes, SB-431542, an inhibitor of TGF- $\beta$ receptor type I (ALK5), reversed the T. cruzi-induced Cx43 reduction [54]. Also, 


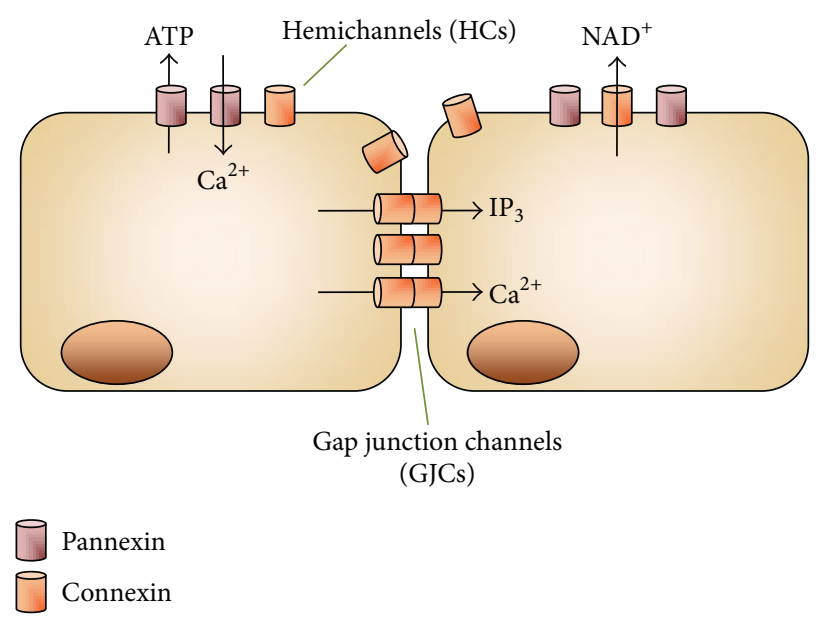

(a) Vertebrates

Connexin

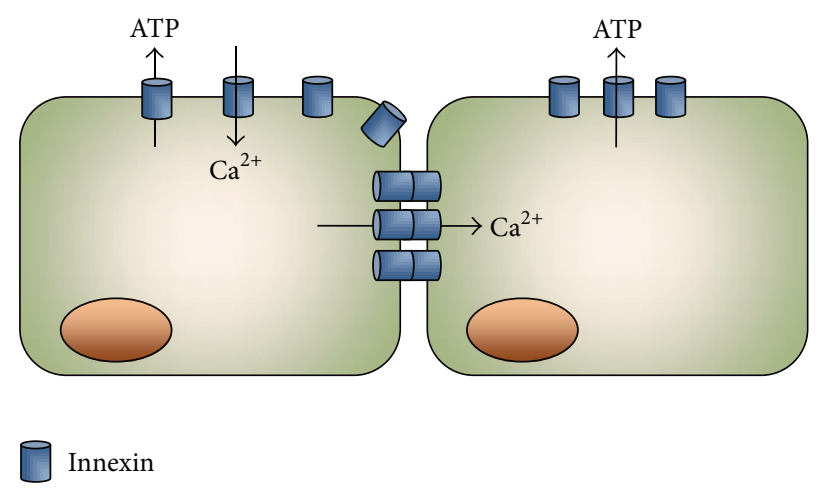

Innexin

(b) Invertebrates

FIGURE 1: Diagram illustrating gap junction channels and hemichannels. The head to head docking of two hemichannels forms a gap junction channel. Each hemichannel is oligohexamer of the protein subunits, pannexins (Panxs) or connexins (Cxs). (a) In vertebrates, Cxs form hemichannels and gap junction channels, whereas Panxs are believed to form only hemichannels. (b) Invertebrates express innexins and they can form hemichannels and gap junction channels. Hemichannels are permeable to ions including $\mathrm{Ca}^{2+}$, and small molecules including signaling ones such as ATP and $\mathrm{NAD}^{+}$. Similarly, gap junction channels are permeable to ions and small molecules including $\mathrm{IP}_{3}$.

treatment with Met-RANTES, a selective CCR1/CCR5 antagonist, significantly ameliorated $\mathrm{Cx} 43$ loss in the heart of $T$. cruzi-infected mice [52]. Similarly, murine knockout models have identified TGF- $\beta$ and TNF- $\alpha$ signaling in gap junctional alterations observed in T. cruzi infection. For example, $\mathrm{Cx} 43$ reduction was not observed in TNF- $\alpha$ receptor 1 null- or anti-TNF- $\alpha$-treated mice infected with Colombian strain of T. cruzi [55]. Similarly, Cx43 expression was unaffected in perforin-deficient mice infected with the Y strain of T. cruzi [53].

3.2. Toxoplasma gondii. Central nervous system toxoplasmosis is a frequent and life-threatening opportunistic infection in immune compromised subjects and is characterized by encephalitis and development of focal brain lesions (e.g., abscess) [63]. Infection by T. gondii caused severe GJ alterations in cells of the central nervous system [50]. Infection with ME49 strain of $T$. gondii decreased the intercellular diffusion of LY in both primary cultured leptomeningeal cells and astrocytes [50]. However, no changes in expression or phosphorylation state of $\mathrm{Cx} 43$ were observed [50]. Staining of cultured astrocytes and leptomeningeal cells showed that $\mathrm{Cx} 43$ immunoreactivity disappeared from appositional membrane areas and Cx26 immunoreactivity was significantly reduced only in parasitized cells. Cx43 and Cx26 normal distribution pattern was maintained in areas of the culture where cells were not parasitized, suggesting a close association between presence of the parasite and impaired intercellular communication [50]. Moreover, brain preparations from mice infected with the ME49 strain of T. gondii, showed complete absence of Cx43 immunoreactivity within the cysts and marked reduction in surrounding tissue [50]. Although little is known about the possible influence of Toxoplasma infection on the expression of other Cxs and Panxs, the current data support the notion of impaired intercellular communication between central nervous system cells with possible impact in tissue homeostasis and normal function.

3.3. Schistosoma mansoni. Schistosomiasis is the second most common parasitic infection of humans after malaria [64]. Various strains such as Schistosoma japonicum, Schistosoma mansoni, and Schistosoma haematobium can induce inflammatory conditions in diverse organs including liver, lung, skin, brain, placenta, gastrointestinal and genitourinary tracts [64].

In mice models, it has been shown that $\mathrm{Cx} 43$ plays a key role in the formation of hepatic granulomas induced by Schistosoma mansoni (S. mansoni) [65]. Schistosomiasis infection occurs through the skin during contact with a cercariae released by the intermediate hosts generally amphibious snail species [64]. The host reacts to eggs and egg products by inducing a Th2-mediated immune response may lead to hepatic granulomatous inflammation and pathological tissue remodeling leading to fibrosis [66]. Interestingly, hepatic granulomas induced by $S$. mansoni in $\mathrm{Cx} 43$ deficient mice present a higher degree of fibrosis and a reduced index of cell proliferation at 8 and 12 weeks after infection [65]. However, no differences in the average area of granulomas or number of cells per granuloma were observed [65]. The authors suggested that deletion of one allele of $\mathrm{Cx} 43$ gene could be the cause of reduced GJ channels that modifies the interactions between granuloma cells, thereby modifying the characteristics of granuloma [65].

\section{Gap Junction Proteins in Parasites}

4.1. Functional Evidence. Ultrastructural identification of GJs has been obtained in flatworms such as Hymenolepis diminuta [58], Diphyllobothrium dendriticum [57], and Taenia solium 


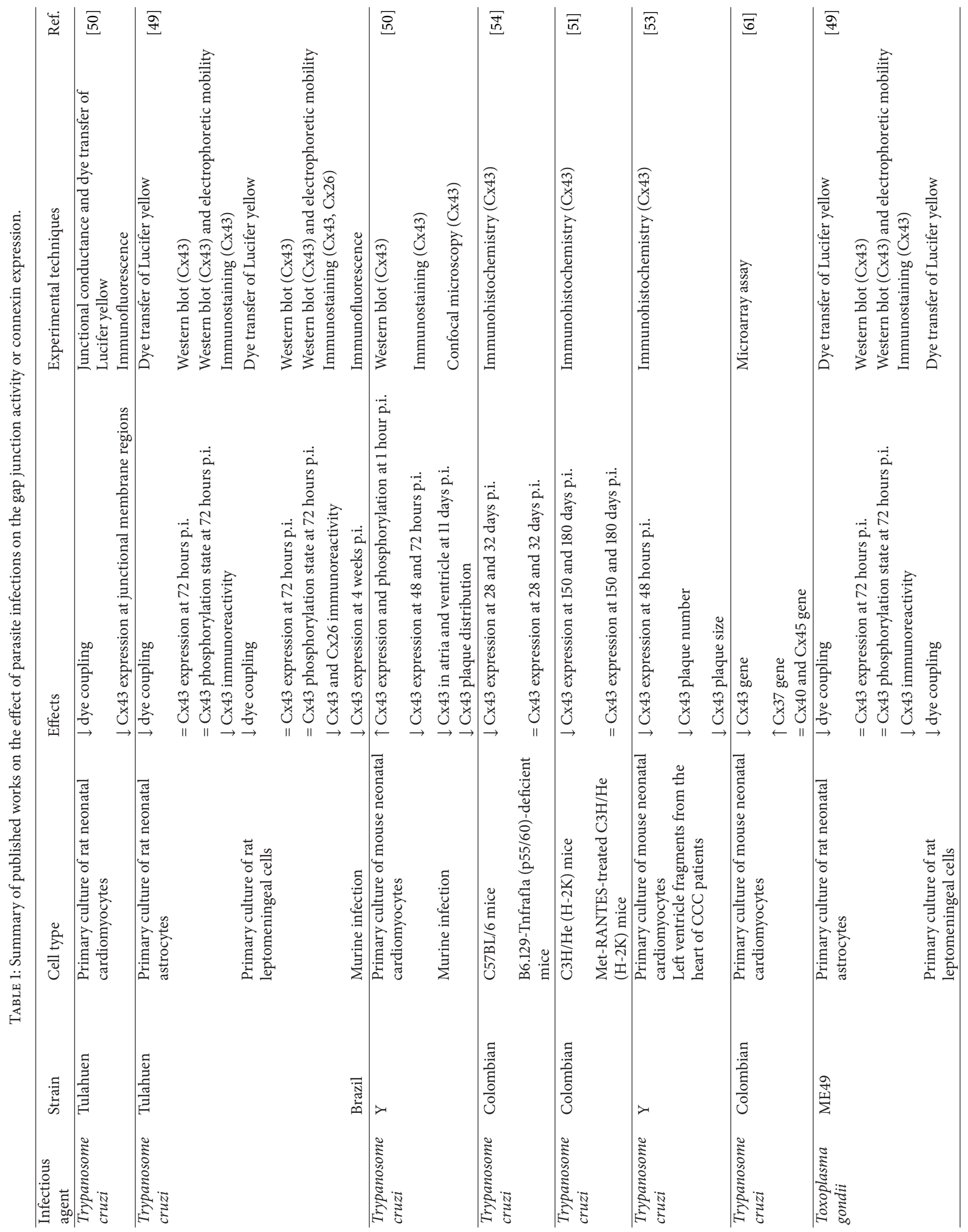




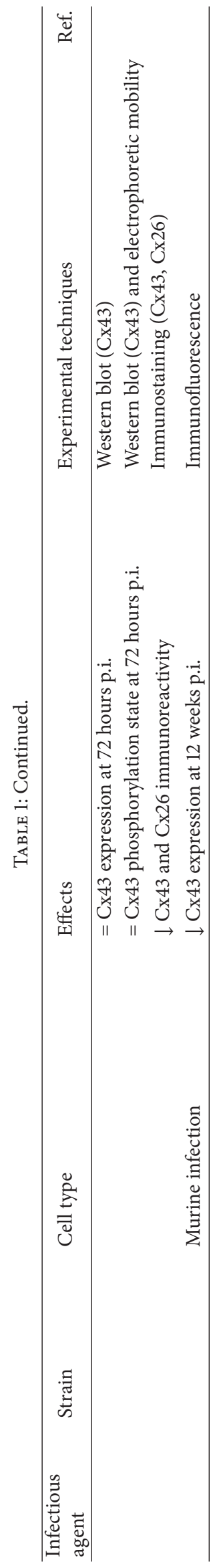


$[59,67]$. Also, the existence of channels reminiscent of GJs between protozoan Trypanosoma musculi and fibroblast has been described [68]. In invertebrates, both GJ channels and hemichannels are formed by Inx proteins [13].

Electron microscopy studies revealed a large number of GJs in the neck and immature proglottids of adult Taenia solium [67]. A large number of Inx/Panx epitopes have been identified in the parenchyma and tegumentary surfaces in both larvae and adults of T. solium. Although it has not been possible to obtain the coding sequences by PCR, the existence of these proteins in flatworms has been demonstrated by western blot analyses [67]. T. solium strobilae showed higher uptake of LY when exposed to elevated glucose [69]. The authors reported that they were unable to determine whether these structures correspond to hemichannels or GJ channels. This result suggests that T. solium also obtains nutrients directly from the mucosal wall, along the whole strobilar tegument [69]. The identification of hemichannel activity and characterization of their permeability properties in T. solium strobilae could be of great relevance for the development of new pharmacological tools.

Moreover, one study suggests the existence of channels reminiscent of GJ channels between Trypanosoma musculi, a parasite specific to mouse, and fibroblasts. This is because LY injected into fibroblast was incorporated into associated trypanosomes [68]. However, the presence of a direct dye transfer pathway has not been demonstrated and might result from dye release to the extracellular space via hemichannels and reuptake also via hemichannels.

4.2. Molecular Evidence. Because some parasite genomes have been sequenced, we searched into the genomic databases for the existence of Inx orthologs and paralogs. The search was performed using the "identify genes by protein motif pattern" option, using as reference the motif YYQW of Inx/Panx or simply using the word innexin. The databases used were GeneDB [70], PlasmoDB [71], and TriTrypDB [72]. The result showed the existence of 195 putative Inx-like genes of which 129 were for Platyhelminths, 11 for Nematodes, 8 for Plasmodium, and 47 for Kinetoplastids. However, no Inx conserved domains were detected in Plasmodium and Kinetoplastids sequences. This suggests that protozoa have no Inx orthologs. Inx genes identified in Platyhelminths were 24 for Taenia solium, 25 for Schistosoma mansoni, 24 for Schistosoma japonicum, 17 for Hymenolepis microstoma, 19 for Echinococcus multilocularis, and 20 for Echinococcus granulosus (Table 2, Figure 4). We also investigated putative genes in arthropods with relevance in parasitology, and we found 5 for Pediculus humanus, 7 for Anopheles gambiae, 4 for Anopheles darlingi, and 6 for Aedes aegypti (Table 2).

\section{Possible Role of Hemichannels in Parasitic Infections}

Because the physiological or pathological role of hemichannels has been proposed only during the last decade, studies on their possible involvement in parasitic infections have not been reported. However, recent studies have shown that hemichannels play an important role in bacterial and viral infections. For example, Cx43 hemichannels increase the internalization of Yersinia enterocolitica in HeLa cells [73] and Cx26 hemichannels increase the invasion and dissemination of Shigella flexneri in epithelial cells $[6,74]$. Also, ${ }^{10}$ Panx1 a peptide that block Panxl hemichannels inhibited human immunodeficiency virus (HIV) invasion and replication in $\mathrm{CD}^{+} \mathrm{T}$ lymphocytes [8]. Although the role of hemichannels in parasitic infections has not been studied, they could participate in responses that include changes in plasma membrane permeability, purinergic or calcium signaling and inflammasome activation. Here, we discuss the possible participation of hemichannels in these cellular processes.

5.1. Host Plasma Membrane Permeability. A common condition and often necessary for infection is the alteration of the host cell membrane permeability $[75,76]$, and hemichannel activity can considerably affect the permeability of the cell membrane in mammalian cells [47].

T. cruzi alters the plasma membrane permeability in host cells during different stages of the disease [76-79]. Infection with T. cruzi reduces junctional conductance between infected cells, as determined by voltage-clamp in cardiomyocyte cell pairs [49]. Moreover, in a chronic model of T.cruziinduced myocarditis, increased membrane permeability was detected through the intense ruthenium red labeling predominantly of the subplasmalemmal zone adjacent to the adherent macrophage [79]. The existence of viable channels reminiscent of GJs between parasite and fibroblast-associated cells in T. musculi, a protozoan parasite specific to mice was also described [68]. Scanning and transmission electron microscopy showed intimate membrane-to-membrane contact between the adherent cells and parasites, and LY transfected into fibroblast could be incorporated into associated trypanosomes in a coculture of $T$. musculi with spleenderived adherent fibroblasts [68]. Other studies have shown that permeabilization of host cells in T. cruzi infections is due to membrane damage, involving $\mathrm{Ca}^{2+}$-dependent exocytosis of lysosomes and delivery of acid sphingomyelinase to the outer leaflet of the cell membrane [76].

To demonstrate whether hemichannels are involved in parasitic-induced plasma membrane alteration, HeLa cells stably transfected with $\mathrm{Cx} 43$ were exposed to metacyclic trypomastigotes of CL Brener strain during 30 minutes. Then, we measured the activity of hemichannels using the ethidium uptake assay (for methodology see [39]). The results revealed that $T$. cruzi increases the ethidium uptake predominantly through hemichannels, since the effect was prominently blocked by $100 \mu \mathrm{M}$ carbenoxolone, a GJ and hemichannel blocker (Figure 2). Of note, dextran-rhodamine, with a molecular mass of $10 \mathrm{kDa}$ (above the exclusion size limit of hemichannels) did not enter into the cells exposed to $T$. cruzi, suggesting that dye uptake was not a result of membrane breakdown (Figure 2). To evaluate the participation of hemichannels in acute T. cruzi infection, we exposed HeLa cells transfected with Cx43 or Panxl to trypomastigotes during 3 hours, and then cells were washed three times with phosphate buffered saline (PBS) solution and incubated in control medium (DMEM 10\% fetal calf serum, 5\% $\mathrm{CO}_{2}$, 
TABLE 2: Innexin putative genes in platyhelminths, nematode, and arthropoda.

\begin{tabular}{|c|c|c|c|}
\hline Organism & Clinical relevance & Gene ID & Description \\
\hline \multicolumn{4}{|l|}{ Platyhelminths } \\
\hline \multirow[t]{24}{*}{ Taenia solium } & Neurocysticercosis & TsM_000900900 & Innexin \\
\hline & & TsM_000901000 & Innexin unc 7 \\
\hline & & TsM_000464200 & Innexin unc 9 \\
\hline & & TsM_000464300 & Innexin unc 9 \\
\hline & & TsM_000569100 & Innexin unc 9 \\
\hline & & TsM_000569300 & Innexin unc 9 \\
\hline & & TsM_000557300 & Innexin unc 9 \\
\hline & & TsM_000954500 & Innexin unc 9 \\
\hline & & TsM_000101700 & Innexin unc 7 \\
\hline & & TsM_001009500 & Innexin unc 7 \\
\hline & & TsM_001009600 & Innexin \\
\hline & & TsM_000471300 & Innexin \\
\hline & & TsM_000116500 & Innexin \\
\hline & & TsM_000916100 & Innexin unc 9 \\
\hline & & TsM_000916200 & Innexin \\
\hline & & TsM_000028400 & Innexin \\
\hline & & TsM_000349500 & Innexin unc 9 \\
\hline & & TsM_000832100 & Innexin unc 9 \\
\hline & & TsM_000811500 & Innexin unc 9 \\
\hline & & TsM_001199700 & Innexin unc 9 \\
\hline & & TsM_000337000 & Innexin \\
\hline & & TsM_000405800 & Innexin unc \\
\hline & & TsM_000655000 & Innexin unc \\
\hline & & TsM_000883500 & Innexin unc 9 \\
\hline \multirow[t]{25}{*}{ Schistosoma mansoni } & Schistosomiasis & Smp_058470 & Innexin unc 7 \\
\hline & & Smp_187190 & Innexin unc 9 \\
\hline & & Smp_141390 & Innexin unc 9 \\
\hline & & Smp_141290 & Innexin \\
\hline & & Smp_141290 & Innexin \\
\hline & & Smp_141290 & Innexin \\
\hline & & Smp_141290 & Innexin \\
\hline & & Smp_140850 & Innexin unc 9 \\
\hline & & Smp_140860 & Innexin unc 9 \\
\hline & & Smp_034610 & Innexin \\
\hline & & Smp_200490 & Innexin \\
\hline & & Smp_129020 & Innexin unc 9 \\
\hline & & Smp_142390 & Innexin unc 9 \\
\hline & & Smp_037510 & Innexin unc 9 \\
\hline & & Smp_146940 & Innexin \\
\hline & & Smp_105760 & Innexin \\
\hline & & Smp_066900 & Innexin unc 9 \\
\hline & & Smp_170070 & Innexin \\
\hline & & Smp_088060 & Innexin unc \\
\hline & & Smp_117170 & Innexin \\
\hline & & Smp_161890 & Innexin \\
\hline & & Smp_073360 & Innexin unc 9 \\
\hline & & Smp_161900 & Innexin unc 9 \\
\hline & & Smp_073380 & Innexin unc 9 \\
\hline & & Smp_026570 & Innexin \\
\hline
\end{tabular}


TABLe 2: Continued.

\begin{tabular}{|c|c|c|c|}
\hline Organism & Clinical relevance & Gene ID & Description \\
\hline \multirow[t]{24}{*}{ Schistosoma japonicum } & \multirow{24}{*}{ Schistosomiasis } & Sjp_0059220 & Innexin-5 \\
\hline & & Sjp_0088670 & Innexin unc 7 \\
\hline & & Sjp_0088360 & Innexin unc 9 \\
\hline & & Sjp_0090890 & Innexin unc 9 \\
\hline & & Sjp_0111560 & Innexin unc 9 \\
\hline & & Sjp_0098040 & Innexin unc 9 \\
\hline & & Sjp_0101240 & Innexin unc 9 \\
\hline & & Sjp_0114320 & Innexin unc 7 \\
\hline & & Sjp_0073220 & Innexin-10 \\
\hline & & Sjp_0073210 & Innexin unc 7 \\
\hline & & Sjp_0076990 & Innexin unc 9 \\
\hline & & Sjp_0103760 & Innexin unc 9 \\
\hline & & Sjp_0131850 & Innexin unc 9 \\
\hline & & Sjp_0104570 & Innexin unc 9 \\
\hline & & Sjp_0112260 & Innexin unc 7 \\
\hline & & Sjp_0111510 & Innexin-5 \\
\hline & & Sjp_0057750 & Innexin unc 7 \\
\hline & & Sjp_0094620 & Innexin unc 7 \\
\hline & & Sjp_0050370 & Innexin unc 7 \\
\hline & & Sjp_0078510 & Innexin unc 9 \\
\hline & & Sjp_0056570 & Innexin unc 9 \\
\hline & & Sjp_0056580 & Innexin \\
\hline & & Sjp_0056560 & Innexin unc 9 \\
\hline & & Sjp_0038790 & Innexin unc 9 \\
\hline \multirow[t]{17}{*}{ Hymenolepis microstoma } & \multirow[t]{17}{*}{ Hymenolepiasis $^{1}$} & HmN_000939600 & Innexin unc 9 \\
\hline & & HmN_000939500 & Innexin unc 9 \\
\hline & & HmN_000878800 & Innexin unc 9 \\
\hline & & HmN_000680500 & Innexin unc 9 \\
\hline & & HmN_000680700 & Innexin 1 \\
\hline & & HmN_000210900 & Innexin unc 9 \\
\hline & & HmN_000053700 & Innexin \\
\hline & & HmN_000555900 & Innexin unc 9 \\
\hline & & HmN_000279100 & Innexin unc 9 \\
\hline & & HmN_000279200 & Innexin unc 9 \\
\hline & & HmN_000602700 & Innexin unc 7 \\
\hline & & HmN_000749400 & Innexin unc 9 \\
\hline & & HmN_000749500 & Innexin unc 9 \\
\hline & & HmN_000749600 & Innexin unc 9 \\
\hline & & HmN_000635700 & Innexin unc 9 \\
\hline & & HmN_000635800 & Innexin \\
\hline & & HmN_000143000 & Innexin unc 7 \\
\hline \multirow[t]{10}{*}{ Echinococcus multilocularis } & \multirow[t]{10}{*}{ Alveolar echinococcosis } & EmuJ_000628300 & Innexin unc 7 \\
\hline & & EmuJ_000628400 & Innexin \\
\hline & & EmuJ_000527700 & Innexin unc 7 \\
\hline & & EmuJ_000448500 & Innexin unc 9 \\
\hline & & EmuJ_000688600 & Innexin \\
\hline & & EmuJ_000688700 & Innexin unc 9 \\
\hline & & EmuJ_000755500 & Innexin unc 9 \\
\hline & & EmuJ_000838500 & Innexin unc 9 \\
\hline & & EmuJ_001000000 & Innexin unc 9 \\
\hline & & EmuJ_000442800 & Innexin unc 7 \\
\hline
\end{tabular}


TABle 2: Continued.

\begin{tabular}{|c|c|c|c|}
\hline Organism & Clinical relevance & Gene ID & Description \\
\hline \multirow[t]{9}{*}{ Echinococcus multilocularis } & Alveolar echinococcosis & EmuJ_000448600 & Innexin unc 9 \\
\hline & & EmuJ_000500900 & Innexin unc 7 \\
\hline & & EmuJ_000501000 & Innexin unc 7 \\
\hline & & EmuJ_000501100 & Innexin unc 9 \\
\hline & & EmuJ_000501300 & Innexin unc 9 \\
\hline & & EmuJ_000231100 & Innexin unc 9 \\
\hline & & EmuJ_000249300 & Innexin \\
\hline & & EmuJ_000249400 & Innexin unc 9 \\
\hline & & EmuJ_000249500 & Innexin unc 9 \\
\hline \multirow[t]{20}{*}{ Echinococcus granulosus } & Cystic echinococcosis & EgrG_000755500 & Innexin unc 9 \\
\hline & & EgrG_000249300 & Innexin \\
\hline & & EgrG_000249400 & Innexin unc 9 \\
\hline & & EgrG_000249500 & Innexin unc 9 \\
\hline & & EgrG_001000000 & Innexin unc 9 \\
\hline & & EgrG_000628300 & Innexin unc 7 \\
\hline & & EgrG_000628400 & Innexin \\
\hline & & EgrG_000527700 & Innexin unc 7 \\
\hline & & EgrG_000527800 & Innexin \\
\hline & & EgrG_000688600 & Innexin \\
\hline & & EgrG_000688700 & Innexin unc 9 \\
\hline & & EgrG_000231100 & Innexin unc 9 \\
\hline & & EgrG_000838500 & Innexin unc 9 \\
\hline & & EgrG_000442800 & Innexin unc 7 \\
\hline & & EgrG_000448500 & Innexin unc 9 \\
\hline & & EgrG_000448600 & Innexin unc 9 \\
\hline & & EgrG_000500900 & Innexin unc 9 \\
\hline & & EgrG_000501000 & Innexin unc 7 \\
\hline & & EgrG_000501100 & Innexin unc 9 \\
\hline & & EgrG_000501300 & Innexin unc 9 \\
\hline \multicolumn{4}{|l|}{ Nematode } \\
\hline \multirow[t]{11}{*}{ Trichinella spiralis } & Trichinosis & EFV61175 & n.d. \\
\hline & & EFV58438 & n.d. \\
\hline & & EFV58160 & n.d. \\
\hline & & EFV57945 & n.d. \\
\hline & & EFV57694 & n.d. \\
\hline & & EFV57592 & n.d. \\
\hline & & EFV56740 & n.d. \\
\hline & & EFV55252 & n.d. \\
\hline & & EFV54644 & n.d. \\
\hline & & EFV52506 & n.d. \\
\hline & & EFV51028 & n.d. \\
\hline \multicolumn{4}{|l|}{ Arthropoda } \\
\hline \multirow[t]{5}{*}{ Pediculus humanus } & Pediculosis & Phum_PHUM336890 & Innexin inx2 \\
\hline & & Phum_PHUM291320 & Innexin inx2 \\
\hline & & Phum_PHUM124530 & Innexin inx2 \\
\hline & & Phum_PHUM124400 & Innexin inxl \\
\hline & & Phum_PHUM124390 & Innexin inx2 \\
\hline \multirow[t]{4}{*}{ Anopheles gambiae } & Vector & AGAP001476 & n.d. \\
\hline & & AGAP001487 (A) & Innexin shaking-B \\
\hline & & AGAP001487 (B) & Innexin shaking-B \\
\hline & & AGAP006241 & n.d. \\
\hline
\end{tabular}


TABLE 2: Continued.

\begin{tabular}{|c|c|c|c|}
\hline Organism & Clinical relevance & Gene ID & Description \\
\hline \multirow[t]{3}{*}{ Anopheles gambiae } & Vector & AGAP001488 & n.d. \\
\hline & & AGAP004510 & n.d. \\
\hline & & AGAP001477 & n.d. \\
\hline \multirow[t]{4}{*}{ Anopheles darlingi } & Vector & ADAR006729 & n.d. \\
\hline & & ADAR000040 & n.d. \\
\hline & & ADAR004464 & n.d. \\
\hline & & ADAR002364 & n.d. \\
\hline \multirow[t]{6}{*}{ Aedes aegypti } & Vector & AAEL011248 & Innexin \\
\hline & & AAEL008588 & Innexin \\
\hline & & AAEL014847 & Innexin \\
\hline & & AAEL006726 & Innexin \\
\hline & & AAEL014227 & Innexin shaking- $B$ \\
\hline & & AAEL014846 & Innexin \\
\hline
\end{tabular}

n.d.: not determined; unc: uncoordinated protein; ${ }^{1}$ rodent tapeworm to the genus Hymenolepis that rarely infects humans.

Incubated with T.cruzi
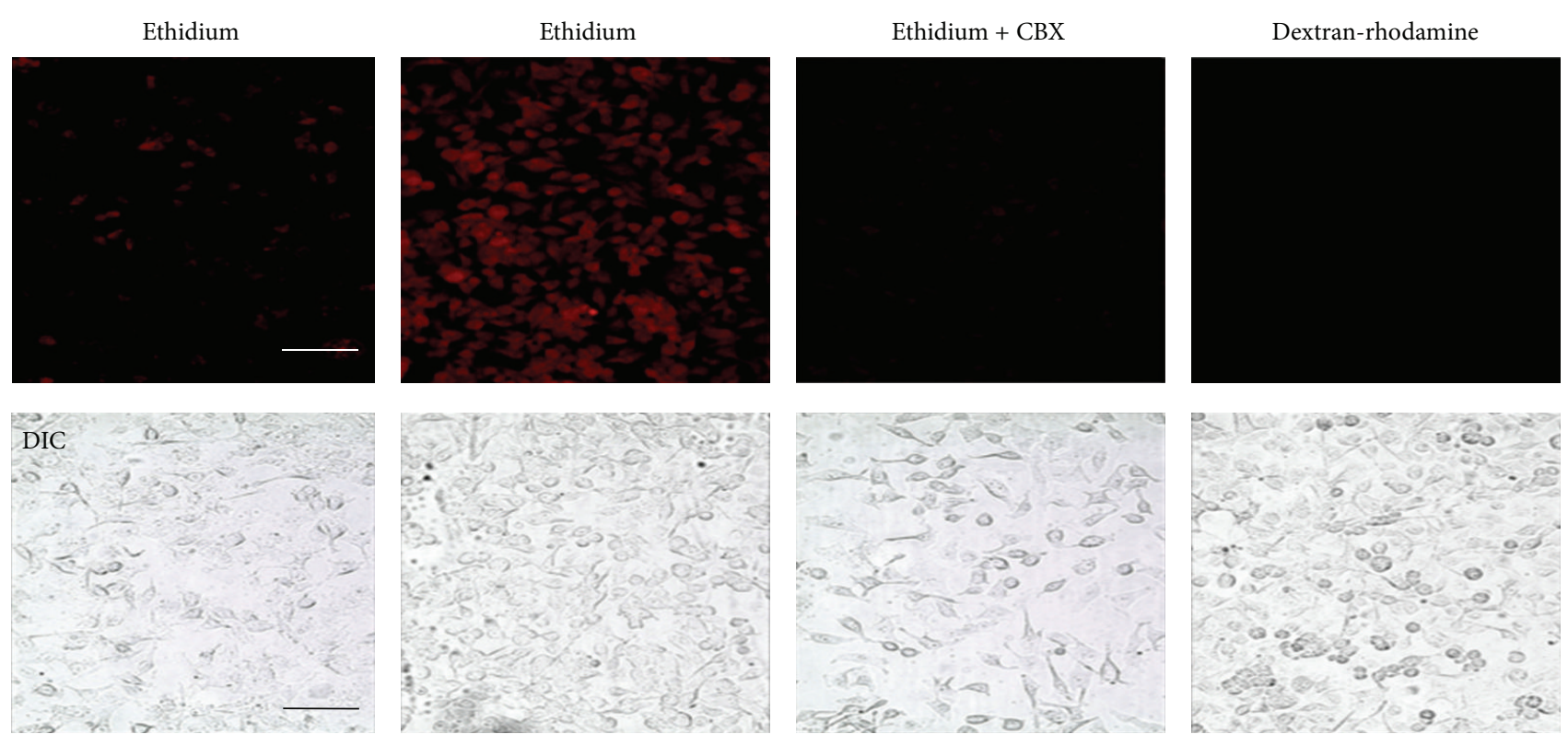

Figure 2: Trypanosoma cruzi increases the ethidium uptake in Cx43 HeLa cells. Representative images of ethidium (red) uptake by Cx43HeLa cells exposed to metacyclic trypomastigotes ( $4: 1$ parasites/cell) of strain CL Brener of $T$. cruzi. In some cases, cells were pretreated with carbenoxolone (100 $\mu \mathrm{M} \mathrm{CBX)} \mathrm{for} 30 \mathrm{~min}$ before exposure to T. cruzi. Dextran-rhodamine dye (10 Kda) was added to demonstrate plasma membrane damage. Note that dextran-rhodamine did not stain the cells, indicating integrity of the cell membranes. Uninfected cells were used as control. Bar: $50 \mu \mathrm{m}$.

$37^{\circ} \mathrm{C}$ ) for additional 48 hours. The numbers of intracellular parasites were then counted at $4 \mathrm{~h}$ (immediately after wash), at 24 and 48 hours of incubation. Notably, the number of intracellular parasites (amastigotes) was $\sim 3$ times higher in HeLa-Cx43 than in parental HeLa cells at 48 hours (150 \pm 5 versus $71 \pm 5$ parasites per cell (Figure 3$)$ ). No differences were observed at 4 or 24 hours. Interestingly, intracellular parasites were not detected in HeLa-Panxl at any incubation time (Figure 3). These results suggest that hemichannels affect parasite cell invasion and/or proliferation. Studies focusing on the molecular mechanisms are required and could open new avenues on chemotherapy of T. cruzi infection.

Another parasite that alters the plasma membrane permeability is Plasmodium falciparum. This parasite invades and replicates asexually within human erythrocytes and enhances plasma membrane permeability in different stages of the disease $[80,81]$. The specific channels responsible for those alterations are controversial and currently are termed 


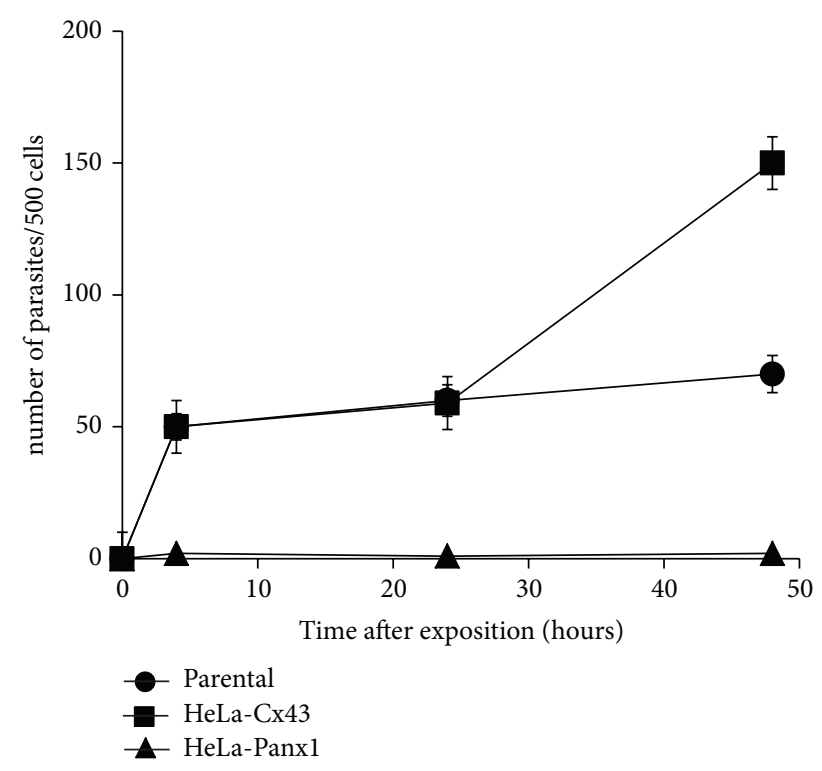

FIgURE 3: Intracellular Trypanosoma cruzi growth depends on type of host hemichannels. HeLa cells transfected with $\mathrm{Cx} 43$, or Panxl were infected with strain Y of T. cruzi, and the number of intracellular parasites was determined at 4,24 , and 48 hours after infection. The number of parasites per infected cell of a total of 500 infected cells is shown.

as new permeability pathways (NPPs) [80, 82, 83]. Some authors have proposed that NPPs are anion-selective channels because malaria-infected erythrocytes exhibit increased anionic channel activity with functional characteristics of a chloride channel, which has been termed plasmodial surface anion channel (PSAC) $[82,84]$. The PSAC exhibits a relatively small unitary conductance $(20 \mathrm{pS})$ in molar $\mathrm{Cl}^{-}$solutions and lower open probabilities at positive membrane potentials [85]. It has been estimated that there are 1,000 and 2,000 functional copies per cell in the infected red blood cell membrane [86]. Based on the observation that showed that NPPs are expressed in the infected cell between 10 to 20 hours after infection and their presence was prevented by inhibition of protein synthesis, other authors proposed that NPPs are formed by parasite proteins inserted into the erythrocyte membrane $[83,87]$. Recently, two clag3 genes from parasite were described as determinants of the NPP/PSAC channel $[88,89]$. The clag3 genes are conserved in all plasmodial species but are absent in other apicomplexan [88]. These genes were identified in blasticidin S-resistant lines of Plasmodium, which exhibited reduced expression of clag genes linked to PSAC activity but had no genome-level changes [89, 90]. Silencing of the protein that forms the channel reduced uptake [89]. Interestingly, the silencing affected other clag genes and showed a novel epigenetic resistance mechanism that involves reduction in host cell uptake [89]. Although the biological role of PSAC was unclear, the absence of this channel in other apicomplexan parasites and higher organisms suggest the channel as a potential highly specific therapeutic target [85].

Currently, it is accepted that different uncharacterized channels mediate changes in plasma membrane permeability

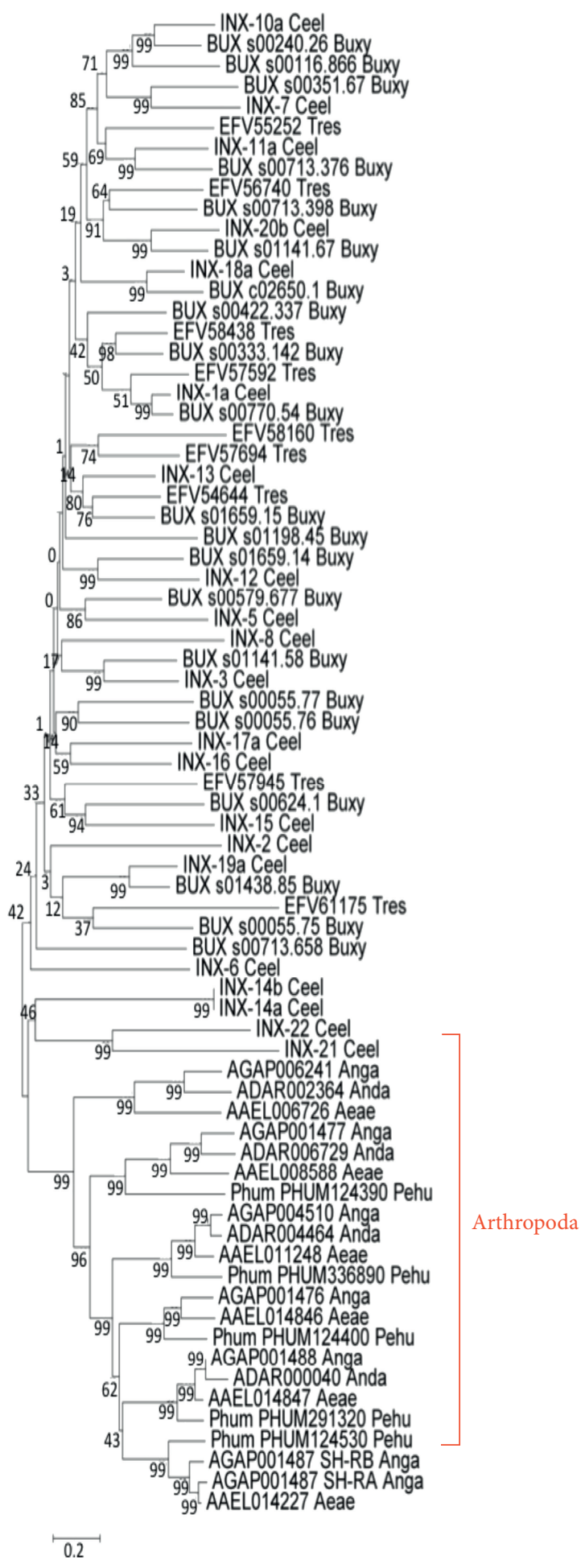

FIGURE 4: Phylogenetic tree of putative innexin sequences, drawn by the NJ algorithm of the megaprogram. The numbers on the nodes indicate the percent recovery of these nodes in 500 bootstrap replications. Species included are: Caenorhabditis elegans (Ceel); Bursaphelenchus xylophilus (Buxy); Trichinella spiralis (Tres); Echinococcus granulosus (Ecgr); Echinococcus multilocularis (Ecmu); Taenia solium (Taso); Hymenolepis microstoma (Hymi); Schistosoma japonicum (Scja); Schistosoma mansoni (Scma); Pediculus humanus (Pehu); Anopheles gambiae (Anga); Anopheles darlingi (Anda); Aedes aegypti (Aeae). The cluster of arthropoda is indicated in red. 
of infected-erythrocytes, and detailed properties have not yet been identified [83]. Potential candidates to explain these changes are Panx-formed hemichannels, since they are present in erythrocytes, are permeable to molecules such a purines, and exhibit anion-like channel activity when expressed in mammalian cells [91, 92]. The apicomplexan Babesia divergens also induces increased erythrocyte permeability [85]. The mechanism for such erythrocyte permeabilization is different in transport rates, solutes selectivity, and temperature dependence compared with the alteration induced by $P$. falciparum [85]. Electrophysiological measurements on Babesia divergens-infected cells indicate that PSAC are not present and conductive anion permeability is not increased [85]. Interestingly, $\left[{ }^{3} \mathrm{H}\right]$-glucose uptake was increased in bovine erythrocytes after Babesia bovis infection, and this effect was not mediated by glucose transporters, because the influx of glucose was not saturable at high concentrations and was unaffected by cytochalasin B or phloretin [93]. Interestingly, it was recently found in skeletal muscle that Panxl hemichannels are permeable to 2-NBDG, a fluorescent glucose derivative and could therefore Panxl hemichannels could explain changes in glucose uptake in red blood cells infected by parasites [36]. Together, these data support the need to explore the possible role of hemichannels in parasite infections.

5.2. Parasitophorous Vacuole Membrane Permeability. Some obligates intracellular parasites, such as Encephalitozoon, Plasmodium, and Toxoplasma live in a parasitophorous vacuole in the host cell [94]. They induce the formation of pores in the parasitophorous vacuole membrane (PVM) that communicate the cytoplasm with the vacuole lumen [94].

Parasites such as Toxoplasma gondii and Plasmodium contain a sorting signal or motif at the $\mathrm{N}$-termini of proteins that facilitates export of proteins to the host cytosol [95, 96]. This motif, known as the host targeting Plasmodium export element (HT/PEXEL), directs Plasmodium or Toxoplasma proteins into host cells to remodel their cytoskeleton, establishes infection, and promotes parasite survival [95, 96]. In Toxoplasma, some proteins that have the motif are not directed to the host cytosol, which indicates a different trafficking mechanism between Toxoplasma and Plasmodium [97]. Plasmodium falciparum exports proteins across the PVM into the erythrocyte cytosol through a protein complex known as Plasmodium translocon of exported proteins (PTEX) [95, 97-99]. This complex is ATP-powered, and comprises heat shock protein 101 (HSP101), PTEX88, PTEX150, exported protein 2 (EXP2), and thioredoxin 2 (TRX2) [97]. Recent studies have also suggested the presence of channellike translocons with similarities to porins and GJ channels $[96,98,99]$.

Assays of microinjection of fluorescent dyes conjugates in the cytosol and subsequent visualization of dye inside the vacuoles have demonstrated the presence of pores in PVM [100]. For example, peptides of $0.8-1.1$ or $0.5 \mathrm{kDa}$ dextran could rapidly enter into the parasitophorous vacuole; however, $10 \mathrm{kDa}$ dextran are excluded [100]. This results indicates that the PVM possesses pores with an exclusion size of $<10 \mathrm{kDa}$ similar to most studied hemichannels [100].
Patch-clamp studies of the PVM from malaria parasites showed large conductance channels (140 pS). Characterization of these channels showed a high capacity and low affinity molecular sieve, and permeability for soluble macromolecules of $>1400 \mathrm{Da}[101,102]$. These conductance and permeability properties resemble those of GJ channels and hemichannels.

In T. gondii infection, the microinjection of LY into the cytoplasm of infected fibroblast showed rapid spreading of the dye into the vacuolar space [103]. Similarly, when the dye was injected directly into the vacuolar space, it was later observed in the cytoplasm [103]. Pretreatment of cells with $5 \mathrm{mM}$ probenecid, a Panxl hemichannel blocker, did not affect the spread of dye into the vacuole, suggesting that Panxl-formed hemichannels are not involved in this phenomenon [103]. Studies focusing on demonstrating the presence of other hemichannels (e.g., Cxs-formed channels) in the PVM could be interesting and relevant to understand the complex host-parasite interaction.

5.3. Intracellular $\mathrm{Ca}^{2+}$ Mobilization. GJs participate in $\mathrm{Ca}^{2+}$ signaling, and they constitute one pathway for intercellular $\mathrm{Ca}^{2+}$ wave propagation in cardiomyocytes, astrocytes, and osteocytes, among other cell types [104]. In addition, Cx26, $\mathrm{Cx} 32$ and $\mathrm{Cx} 43$ hemichannels are permeable to $\mathrm{Ca}^{2+}[105-$ 108]. Purified Cx43 hemichannels reconstituted into unilamellar liposomes loaded with Calcium Green-2, a $\mathrm{Ca}^{2+}$ indicator, showed that an increase between 5 to $20 \mu \mathrm{M}$ in extraliposomal $\mathrm{Ca}^{2+}$ concentration causes a 2 -fold increase in Green-2 fluorescence, demonstrating that $\mathrm{Cx} 43$ hemichannels are permeable to $\mathrm{Ca}^{2+}$ [107]. In protozoan infections, a key process in early stages of invasion is the rise in cytosolic free $\mathrm{Ca}^{2+}$ concentration [109]. For example, when T. cruzi comes into contact with the host cell, triggers a transient increase in cytosolic free $\mathrm{Ca}^{2+}$ concentration that induces host cell lysosome exocytosis [76, 109]. This process is required for cell invasion, because chelating the intracellular $\mathrm{Ca}^{2+}$ transients in host cells reduces the entry of the parasite into the cell [110]. In cardiomyocytes, T. cruzi infection induces $\mathrm{Ca}^{2+}$ fluxes and causes myofibrillar breakdown disturbing contractility [111]. Also, the intracellular free $\mathrm{Ca}^{2+}$ concentration is important in T. gondii infections. During invasion, the parasite induces a significant increase in cytosolic free $\mathrm{Ca}^{2+}$ concentration in phagocytic cells $[112,113]$. In dendritic cells, a lysate of $T$. gondii induces an increase of intracellular free $\mathrm{Ca}^{2+}$ signal [114]. Moreover, the parasite egress can be artificially induced by the use of ionophores $[115,116]$. Since all studied hemichannels are sensitive to $\mathrm{Ca}^{2+}$ and also allow passage of $\mathrm{Ca}^{2+}$, they could participate in key processes such as invasion in parasite infections of most tissues.

5.4. Activation of Inflammasome. The inflammasome has been proposed such a key multiprotein complex involved in innate immunity [30, 117]. Inflammasome activation triggers innate immune defense by inducing the processing of proinflammatory cytokines, such as IL-1, in a caspase 1-dependent manner [117]. Panxl hemichannels play 
a key role in inflammasome activation [117]. It has been proposed that small pathogen-associated molecule patterns (PAMPs) can gain cytosolic access via the $\mathrm{P} 2 \mathrm{X}_{7}$ receptor/Panxl hemichannel $\left(\mathrm{P}_{2} \mathrm{X}_{7} / \mathrm{Panx} 1\right)$ complex and activate the inflammasome [117]. It has also been described that ATP release through $\mathrm{P} 2 \mathrm{X}_{7} / \mathrm{Panxl}$ hemichannels can promote NLR-mediated inflammasome assembly [118, 119]. Recently, some studies have begun to elucidate the role of inflammasome in parasite infection [120]. For example, NALP1 (NACHT-LRR-PYD-containing protein-1)-mediated inflammasome activation is critical for mediating innate immune response to T. gondii [120]. NALP1 silencing with siRNA, attenuated the progression of $T$. gondii infection, with accelerated host cell death and eventual cell disintegration. In this study T. gondii infection was not observed in monocytic cells with NALP1 knockdown [120]. In addition, malarial hemozoin activates the NLRP3 (NOD-like receptor pyrin domain containing three) inflammasome through Src family kinases [121]. These studies are the first demonstration of the role of inflammasome in parasitic infections. However, the possible relevance of $\mathrm{P}_{2} \mathrm{X}_{7} / \mathrm{Panxl}$-induced inflammasome activation in parasitic infections remains to be determined.

\section{Conclusions and Perspectives}

Parasitic infections affect predominantly underprivileged areas of the world, but attention has been increasing lately due to the rise in people migration habits, intercontinental travels, and immune suppressed patients. Parasitic infections represent serious life threatening conditions in high risk groups such as young children, elderly, and immune deficient subjects, and therapeutic options include a wide variety of compounds with considerable toxicity and side effects. The introduction of new methods, specific inhibitors, and the use of knockout animals has increased our understanding about the role of hemichannels in pathophysiological infectious conditions such as viral and bacterial infections. However, their role in parasitic infections has not yet been explored. Hemichannels are involved in the regulation of plasma membrane permeability in ischemic insults, metabolic inhibition, and cerebral stroke $[122,123]$. Under these conditions, the deregulated hemichannel opening increases the cell damage through imbalances in transmembrane electrochemical gradients [35, 123]. Alterations of plasma membrane is a common phenomenon in parasite-induced infections such malaria and T. cruzi, among others [81, 124]. In addition, we have shown here for the first time to our knowledge that T. cruzi induces opening of Cx43 hemichannels in HeLa cells. Hemichannels could be key players in parasite-induced plasma membrane permeabilization, consequent activation of inflammasome, and cell degeneration. Hemichannels play a key role in $\mathrm{Ca}^{2+}$ influx into cells under different conditions such ischemic damage [108]. Moreover, elevations of intracellular $\mathrm{Ca}^{2+}$ in the host are required for invasion several parasites that include T. gondii and T. cruzi, among others $[109,114]$. Hemichannels could serve as prominent pathways for $\mathrm{Ca}^{2+}$ entry facilitating the above-mentioned processes. Pannexin-1 hemichannels are crucial for inflammasome activation [125]. This cytosolic multiprotein complex is a critical for the innate defense against pathogens [126], suggesting that hemichannels could also be involved in innate defense against parasitic infections. Accordingly hemichannels are regulated by inflammatory cytokines (IL-1 $\beta$ and TNF-alpha) [37], and parasitic infections promote inflammatory responses. All the above data support the importance of studying the possible role of hemichannels in parasitic infections. They could be important in the invasion, replication, or pathogenesis, especially in protozoan infection. Moreover, they are potential targets for the development of new compounds to limit parasite infections or tissue/organ damage induced by their presence.

\section{Acknowledgments}

We would like to thank Ms. Paola Fernández and Ms. Teresa Vergara for their technical support. This work was funded by the FONDECYT (No. 1111033 to J.C.S., No. 1131007 to J.G. and No. 3120006 to J.L.V.), Anillo (ACT71 to J.C.S.), Chilean Science Millennium Institute (P09-022-F to J.C.S.), Fondef (DO7I1086 to J.C.S.) and CODEI (5381 to J.G. and J.L.V) grants.

\section{References}

[1] J. C. Sáez, V. M. Berthoud, M. C. Brañes, A. D. Martínez, and E. C. Beyer, "Plasma membrane channels formed by connexins: their regulation and functions," Physiological Reviews, vol. 83, no. 4, pp. 1359-1400, 2003.

[2] S. Kanno and J. E. Saffitz, "The role of myocardial gap junctions in electrical conduction and arrhythmogenesis," Cardiovascular Pathology, vol. 10, no. 4, pp. 169-177, 2001.

[3] M. V. L. Bennett, J. M. Garré, J. A. Orellana, F. F. Bukauskas, M. Nedergaard, and J. C. Sáez, "Connexin and pannexin hemichannels in inflammatory responses of glia and neurons," Brain Research, vol. 1487, pp. 3-15, 2012.

[4] R. Elgueta, J. A. Tobar, K. F. Shoji et al., "Gap junctions at the dendritic cell-T cell interface are key elements for antigendependent T cell activation," Journal of Immunology, vol. 183, no. 1, pp. 277-284, 2009.

[5] J. M. Churko and D. W. Laird, "Gap junction remodeling in skin repair following wounding and disease," Physiology, vol. 28, pp. 190-198, 2013.

[6] G. T. Van Nhieu, C. Clair, R. Bruzzone, M. Mesnil, P. Sansonetti, and L. Combettes, "Connexin-dependent inter-cellular communication increases invasion and dissemination of Shigella in epithelial cells," Nature Cell Biology, vol. 5, no. 8, pp. 720-726, 2003.

[7] J. A. Guttman, A. E.-J. Lin, Y. Li et al., "Gap junction hemichannels contribute to the generation of diarrhoea during infectious enteric disease," Gut, vol. 59, no. 2, pp. 218-226, 2010.

[8] J. A. Orellana, S. Velasquez, D. W. Williams, J. C. Sáez, and J. W. Berman, "Pannexinl hemichannels are critical for HIV infection of human primary $\mathrm{CD} 4{ }^{+} \mathrm{T}$ lymphocytes," Journal of Leukocyte Biology, vol. 94, no. 3, pp. 399-407, 2013.

[9] D. A. Goodenough, J. A. Goliger, and D. L. Paul, "Connexins, connexons, and intercellular communication," Annual Review of Biochemistry, vol. 65, pp. 475-502, 1996. 
[10] K. Willecke, J. Eiberger, J. Degen et al., "Structural and functional diversity of connexin genes in the mouse and human genome," Biological Chemistry, vol. 383, no. 5, pp. 725-737, 2002.

[11] S. Penuela, R. Gehi, and D. W. Laird, "The biochemistry and function of pannexin channels," Biochimica et Biophysica Acta, vol. 1828, pp. 15-22, 2012.

[12] P. Phelan and T. A. Starich, "Innexins get into the gap," BioEssays, vol. 23, no. 5, pp. 388-396, 2001.

[13] P. Phelan, "Innexins: members of an evolutionarily conserved family of gap-junction proteins," Biochimica et Biophysica Acta, vol. 1711, no. 2, pp. 225-245, 2005.

[14] R. G. Johnson, J. K. Reynhout, E. M. TenBroek et al., "Gap junction assembly: roles for the formation plaque and regulation by the C-terminus of connexin43," Molecular Biology of the Cell, vol. 23, no. 1, pp. 71-86, 2012.

[15] R. Araya, D. Eckardt, S. Maxeiner et al., "Expression of connexins during differentiation and regeneration of skeletal muscle: functional relevance of connexin43," Journal of Cell Science, vol. 118, no. 1, pp. 27-37, 2005.

[16] S. A. Murray, K. Davis, and V. Gay, "ACTH and adrenocortical gap junctions," Microscopy Research and Technique, vol. 61, no. 3, pp. 240-246, 2003.

[17] E. Gershon, V. Plaks, and N. Dekel, "Gap junctions in the ovary: expression, localization and function," Molecular and Cellular Endocrinology, vol. 282, no. 1-2, pp. 18-25, 2008.

[18] D. P. Kelsell, J. Dunlop, H. P. Stevens et al., "Connexin 26 mutations in hereditary non-syndromic sensorineural deafness," Nature, vol. 387, no. 6628, pp. 80-83, 1997.

[19] C.-H. Xia, B. Chang, A. M. Derosa, C. Cheng, T. W. White, and X. Gong, "Cataracts and microphthalmia caused by a Gja 8 mutation in extracellular loop 2," PLoS ONE, vol. 7, Article ID e52894, 2012.

[20] C. A. Scott, D. Tattersall, E. A. O’Toole, and D. P. Kelsell, “Connexins in epidermal homeostasis and skin disease," Biochimica et Biophysica Acta, vol. 1818, pp. 1952-1961, 2012.

[21] C. C. Naus and D. W. Laird, "Implications and challenges of connexin connections to cancer," Nature Reviews Cancer, vol. 10, no. 6, pp. 435-441, 2010.

[22] E. A. Eugenin, D. Basilio, J. C. Sáez et al., "The role of gap junction channels during physiologic and pathologic conditions of the human central nervous system," Journal of Neuroimmune Pharmacology, pp. 1-20, 2012.

[23] G. Meșe, G. Richard, and T. W. White, "Gap junctions: basic structure and function," Journal of Investigative Dermatology, vol. 127, no. 11, pp. 2516-2524, 2007.

[24] J. A. Orellana, A. D. Martinez, and M. A. Retamal, “Gap junction channels and hemichannels in the CNS: regulation by signaling molecules," Neuropharmacology, 2013.

[25] J. A. Orellana, P. J. Sáez, K. F. Shoji et al., "Modulation of brain hemichannels and gap junction channels by pro-inflammatory agents and their possible role in neurodegeneration," Antioxidants and Redox Signaling, vol. 11, no. 2, pp. 369-399, 2009.

[26] R. Kar, N. Batra, M. A. Riquelme, and J. X. Jiang, "Biological role of connexin intercellular channels and hemichannels," Archives of Biochemistry and Biophysics, vol. 524, pp. 2-15, 2012.

[27] N. Wang, M. De Bock, E. Decrock et al., "Paracrine signaling through plasma membrane hemichannels," Biochimica et Biophysica Acta, vol. 1828, pp. 35-50, 2013.

[28] A. P. Quist, S. K. Rhee, H. Lin, and R. Lal, "Physiological role of gap-junctional hemichannels: extracellular calcium-dependent isosmotic volume regulation," Journal of Cell Biology, vol. 148, no. 5, pp. 1063-1074, 2000.
[29] M. Billaud, J. K. Sandilos, and B. E. Isakson, "Pannexin 1 in the regulation of vascular tone," Trends in Cardiovascular Medicine, vol. 22, pp. 68-72, 2012.

[30] W. R. Silverman, J. P. de Rivero Vaccari, S. Locovei et al., “The pannexin 1 channel activates the inflammasome in neurons and astrocytes," Journal of Biological Chemistry, vol. 284, no. 27, pp. 18143-18151, 2009.

[31] L. Franco, E. Zocchi, C. Usai et al., "Paracrine roles of NAD+ and cyclic ADP-ribose in increasing intracellular calcium and enhancing cell proliferation of 3T3 fibroblasts," Journal of Biological Chemistry, vol. 276, no. 24, pp. 21642-21648, 2001.

[32] R. A. Pearson, N. Dale, E. Llaudet, and P. Mobbs, "ATP released via gap junction hemichannels from the pigment epithelium regulates neural retinal progenitor proliferation," Neuron, vol. 46, no. 5, pp. 731-744, 2005.

[33] X. Li, F. R. Heinzel, K. Boengler, R. Schulz, and G. Heusch, "Role of connexin 43 in ischemic preconditioning does not involve intercellular communication through gap junctions," Journal of Molecular and Cellular Cardiology, vol. 36, no. 1, pp. 161-163, 2004.

[34] S. C. Schock, D. LeBlanc, A. M. Hakim, and C. S. Thompson, "ATP release by way of connexin 36 hemichannels mediates ischemic tolerance in vitro," Biochemical and Biophysical Research Communications, vol. 368, no. 1, pp. 138-144, 2008.

[35] J. A. Orellana, X. F. Figueroa, H. A. Sánchez, S. ContrerasDuarte, V. Velarde, and J. C. Sáez, "Hemichannels in the neurovascular unit and white matter under normal and inflamed conditions," CNS and Neurological Disorders, vol. 10, no. 3, pp. 404-414, 2011.

[36] M. A. Riquelme, L. A. Cea, J. L. Vega et al., “The ATP required for potentiation of skeletal muscle contraction is released via pannexin hemichannels," Neuropharmacology, 2013.

[37] M. A. Retamal, N. Froger, N. Palacios-Prado et al., "Cx43 hemichannels and gap junction channels in astrocytes are regulated oppositely by proinflammatory cytokines released from activated microglia," Journal of Neuroscience, vol. 27, no. 50, pp. 13781-13792, 2007.

[38] N. Froger, J. A. Orellana, C.-F. Calvo et al., "Inhibition of cytokine-induced connexin 43 hemichannel activity in astrocytes is neuroprotective," Molecular and Cellular Neuroscience, vol. 45, no. 1, pp. 37-46, 2010.

[39] J. A. Orellana, K. F. Shoji, V. Abudara et al., "Amyloid $\beta$-induced death in neurons involves glial and neuronal hemichannels," Journal of Neuroscience, vol. 31, no. 13, pp. 4962-4977, 2011.

[40] G. Hawat, M. Benderdour, G. Rousseau, and G. Baroudi, "Connexin 43 mimetic peptide Gap26 confers protection to intact heart against myocardial ischemia injury," Pflugers Archiv European Journal of Physiology, vol. 460, no. 3, pp. 583-592, 2010.

[41] K. Przyklenk, M. Maynard, C. E. Darling, and P. Whittaker, "Pretreatment with D-myo-inositol trisphosphate reduces infarct size in rabbit hearts: role of inositol trisphosphate receptors and gap junctions in triggering protection," Journal of Pharmacology and Experimental Therapeutics, vol. 314, no. 3, pp. 1386-1392, 2005.

[42] K. Shintani-Ishida, K. Uemura, and K.-I. Yoshida, "Hemichannels in cardiomyocytes open transiently during ischemia and contribute to reperfusion injury following brief ischemia," American Journal of Physiology: Heart and Circulatory Physiology, vol. 293, no. 3, pp. H1714-H1720, 2007.

[43] N. Wang, N. Wang, E. De Vuyst et al., "Selective inhibition of Cx43 hemichannels by Gap19 and its impact on myocardial 
ischemia/reperfusion injury," Basic Research in Cardiology, vol. 108, article 309, 2013.

[44] L. A. Cea, M. A. Riquelme, B. A. Cisterna et al., "Connexin- and pannexin-based channels in normal skeletal muscles and their possible role in muscle atrophy," Journal of Membrane Biology, vol. 245, pp. 423-436, 2012.

[45] J. C. Sáez, K. A. Schalper, M. A. Retamal, J. A. Orellana, K. F. Shoji, and M. V. L. Bennett, "Cell membrane permeabilization via connexin hemichannels in living and dying cells," Experimental Cell Research, vol. 316, no. 15, pp. 2377-2389, 2010.

[46] G. E. Sosinsky, D. Boassa, R. Dermietzel et al., "Pannexin channels are not gap junction hemichannels," Channels, vol. 5, no. 3, pp. 193-197, 2011.

[47] K. A. Schalper, J. A. Orellana, V. M. Berthoud, and J. C. Sáez, "Dysfunctions of the diffusional membrane pathways mediated hemichanels in inherited and acquired diseases," Current Vascular Pharmacology, vol. 7, no. 4, pp. 486-505, 2009.

[48] J. M. Bethony, R. N. Cole, X. Guo et al., "Vaccines to combat the neglected tropical diseases," Immunological Reviews, vol. 239, no. 1, pp. 237-270, 2011.

[49] D. Adesse, L. R. Garzoni, H. Huang, H. B. Tanowitz, M. de Nazareth Meirelles, and D. C. Spray, "Trypanosoma cruzi induces changes in cardiac connexin 43 expression," Microbes and Infection, vol. 10, no. 1, pp. 21-28, 2008.

[50] A. C. De Campos Carvalho, C. Roy, E. L. Hertzberg et al., "Gap junction disappearance in astrocytes and leptomeningeal cells as a consequence of protozoan infection," Brain Research, vol. 790, no. 1-2, pp. 304-314, 1998.

[51] A. C. Campos de Carvalho, H. B. Tanowitz, M. Wittner et al., "Gap junction distribution is altered between cardiac myocytes infected with Trypanosoma cruzi," Circulation Research, vol. 70, no. 4, pp. 733-742, 1992.

[52] G. A. Medeiros, J. C. Silvério, A. P. M. P. Marino et al., "Treatment of chronically Trypanosoma cruzi-infected mice with a CCR1/CCR5 antagonist (Met-RANTES) results in amelioration of cardiac tissue damage," Microbes and Infection, vol. 11, no. 2, pp. 264-273, 2009.

[53] J. C. Silverio, L. M. De-Oliveira-Pinto, A. A. Da Silva, G. M. De Oliveira, and J. Lannes-Vieira, "Perforin-expressing cytotoxic cells contribute to chronic cardiomyopathy in Trypanosoma cruzi infection," International Journal of Experimental Pathology, vol. 91, no. 1, pp. 72-86, 2010.

[54] M. C. Waghabi, R. Coutinho-Silva, J.-J. Feige et al., "Gap junction reduction in cardiomyocytes following transforming growth factor- $\beta$ treatment and Trypanosoma cruzi infection," Memorias do Instituto Oswaldo Cruz, vol. 104, no. 8, pp. 10831090, 2009.

[55] K. Kroll-Palhares, J. C. Silvério, A. A. Da Silva et al., "TNF/TNFR1 signaling up-regulates CCR5 expression by CD ${ }^{+}$ $\mathrm{T}$ lymphocytes and promotes heart tissue damage during Trypanosoma cruzi infection: beneficial effects of TNF- $\alpha$ blockade," Memorias do Instituto Oswaldo Cruz, vol. 103, no. 4, pp. 375-385, 2008.

[56] A. J. Burns, C. V. Howard, J. M. Allen, D. Van Velsen, and G. McKerr, "Stereological estimation of gap junction surface area per neuron in the developing nervous system of the invertebrate Mesocestoides corti," Parasitology, vol. 111, no. 4, pp. 505-513, 1995.

[57] P. Lindroos, "Observations on the extracellular spaces and intercellular junctions in Diphyllobothrium dendriticum (Cestoda)," Acta Zoologica, vol. 65, no. 3, pp. 153-158, 1984.
[58] K. S. Richards and C. Arme, "Junctional complexes in the inner cyst tissue of the cysticercoid of Hymenolepis diminuta (Cestoda)," Parasitology, vol. 87, no. 2, pp. 295-306, 1983.

[59] K. Willms, L. Robert, and J. A. Caro, "Ultrastructure of smooth muscle, gap junctions and glycogen distribution in Taenia solium tapeworms from experimentally infected hamsters," Parasitology Research, vol. 89, no. 4, pp. 308-316, 2003.

[60] A. Rassi Jr., A. Rassi, and J. A. Marin-Neto, "Chagas disease," The Lancet, vol. 375, no. 9723, pp. 1388-1402, 2010.

[61] R. C. D. S. Goldenberg, D. A. Iacobas, S. Iacobas et al., “Transcriptomic alterations in Trypanosoma cruzi-infected cardiac myocytes," Microbes and Infection, vol. 11, no. 14-15, pp. 11401149, 2009.

[62] D. Adesse, R. C. Goldenberg, F. S. Fortes et al., "Gap junctions and chagas disease," Advances in Parasitology, vol. 76, pp. 63-81, 2011.

[63] S. A. Elmore, J. L. Jones, P. A. Conrad, S. Patton, D. S. Lindsay, and J. P. Dubey, "Toxoplasma gondii: epidemiology, feline clinical aspects, and prevention," Trends in Parasitology, vol. 26, no. 4, pp. 190-196, 2010.

[64] B. Gryseels, K. Polman, J. Clerinx, and L. Kestens, "Human schistosomiasis," The Lancet, vol. 368, no. 9541, pp. 1106-1118, 2006.

[65] S. C. S. Oloris, M. Mesnil, V. N. D. S. Reis et al., "Hepatic granulomas induced by Schistosoma mansoni in mice deficient for connexin 43 present lower cell proliferation and higher collagen content," Life Sciences, vol. 80, no. 13, pp. 1228-1235, 2007.

[66] M. H. J. Meevissen, M. Yazdanbakhsh, and C. H. Hokke, "Schistosoma mansoni egg glycoproteins and C-type lectins of host immune cells: molecular partners that shape immune responses," Experimental Parasitology, vol. 132, pp. 14-21, 2012.

[67] R. Zurabian, A. Landa, L. Robert, and K. Willms, "Immunolocalization of Taenia solium gap junction innexins," Parasitology, vol. 135, no. 9, pp. 1125-1131, 2008.

[68] A. Gugssa, C. M. Lee, S. Gebru et al., "Co-culture of Trypanosoma musculi with spleen-derived adherent fibroblasts: possible transfer of small molecules via connexons," Journal of Submicroscopic Cytology and Pathology, vol. 37, no. 3-4, pp. 223229, 2005.

[69] K. Willms, K. Willms, A. M. F. Presas et al., "Taeniid tapeworm responses to in vitro glucose," Parasitology Research, vol. 96, pp. 296-301, 2005.

[70] F. J. Logan-Klumpler, N. De Silva, and U. Boehme, "GeneDBan annotation database for pathogens," Nucleic Acids Research, vol. 40, pp. D98-D108, 2012.

[71] C. Aurrecoechea, J. Brestelli, B. P. Brunk et al., "PlasmoDB: a functional genomic database for malaria parasites," Nucleic Acids Research, vol. 37, no. 1, pp. D539-D543, 2009.

[72] M. Aslett, C. Aurrecoechea, M. Berriman et al., "TriTrypDB: a functional genomic resource for the Trypanosomatidae," Nucleic Acids Research, vol. 38, no. 1, pp. D457-D462, 2009.

[73] L. A. Velasquez Almonacid, S. Tafuri, L. Dipineto et al., "Role of connexin-43 hemichannels in the pathogenesis of Yersinia enterocolitica," Veterinary Journal, vol. 182, no. 3, pp. 452-457, 2009.

[74] C. Simpson, D. P. Kelsell, and O. Marchès, "Connexin 26 facilitates gastrointestinal bacterial infection in vitro," Cell and Tissue Research, vol. 351, pp. 107-116, 2013.

[75] A. Alkhalil, D. A. Hill, and S. A. Desai, "Babesia and plasmodia increase host erythrocyte permeability through distinct mechanisms," Cellular Microbiology, vol. 9, no. 4, pp. 851-860, 2007. 
[76] M. C. Fernandes, M. Cortez, A. R. Flannery, C. Tam, R. A. Mortara, and N. W. Andrews, "Trypanosoma cruzi subverts the sphingomyelinase-mediated plasma membrane repair pathway for cell invasion," Journal of Experimental Medicine, vol. 208, no. 5, pp. 909-921, 2011.

[77] J. Costales and E. C. Rowland, "A role for protease activity and host-cell permeability during the process of Trypanosoma cruzi egress from infected cells," Journal of Parasitology, vol. 93, no. 6, pp. 1350-1359, 2007.

[78] A. Osuna, M. N. Rodríguez-Cabezas, S. Castanys, M. C. MesaValle, and M. C. Mascaro, "A protein secreted by Trypanosoma cruzi capable of inducing the entry of inert particles into HeLa cells," International Journal for Parasitology, vol. 25, no. 10, pp. 1213-1225, 1995.

[79] M. A. Rossi and J. S. Silva, "Permeability alteration of the sarcolemmal membrane, particularly at the site of macrophage contact, in experimental chronic Trypanosoma cruzi myocarditis in mice," International Journal of Experimental Pathology, vol. 71, no. 4, pp. 545-555, 1990.

[80] Z. I. Cabantchik, "Altered membrane transport of malariainfected erythrocytes: a possible pharmacologic target," Blood, vol. 74, no. 5, pp. 1464-1471, 1989.

[81] H. Ginsberg, "Alterations caused by the intraerythrocytic malaria parasite in the permeability of its host cell membrane," Comparative Biochemistry and Physiology, vol. 95, no. 1, pp. 3139, 1990.

[82] K. Kirk, H. A. Horner, B. C. Elford, J. C. Ellory, and C. I. Newbold, "Transport of diverse substrates into malaria-infected erythrocytes via a pathway showing functional characteristics of a chloride channel," Journal of Biological Chemistry, vol. 269, no. 5, pp. 3339-3347, 1994.

[83] H. M. Staines, A. Alkhalil, R. J. Allen et al., "Electrophysiological studies of malaria parasite-infected erythrocytes: current status," International Journal for Parasitology, vol. 37, no. 5, pp. 475-482, 2007.

[84] S. A. Desai, S. M. Bezrukov, and J. Zimmerberg, "A voltagedependent channel involved in nutrient uptake by red blood cells infected with the malaria parasite," Nature, vol. 406, no. 6799, pp. 1001-1005, 2000.

[85] A. Alkhalil, J. V. Cohn, M. A. Wagner, J. S. Cabrera, T. Rajapandi, and S. A. Desai, "Plasmodium falciparum likely encodes the principal anion channel on infected human erythrocytes," Blood, vol. 104, no. 13, pp. 4279-4286, 2004.

[86] D. A. Hill, A. D. Pillai, F. Nawaz et al., "A blasticidin S-resistant Plasmodium falciparum mutant with a defective plasmodial surface anion channel," Proceedings of the National Academy of Sciences of the United States of America, vol. 104, no. 3, pp. 10631068, 2007.

[87] W. V. Breuer, S. Kutner, J. Sylphen, H. Ginsburg, and Z. I. Cabantchik, "Covalent modification of the permeability pathways induced in the human erythrocyte membrane by the malarial parasite Plasmodium falciparum," Journal of Cellular Physiology, vol. 133, no. 1, pp. 55-63, 1987.

[88] W. Nguitragool, A. A. B. Bokhari, A. D. Pillai et al., "Malaria parasite clag3 genes determine channel-mediated nutrient uptake by infected red blood cells," Cell, vol. 145, no. 5, pp. 665-677, 2011.

[89] P. Sharma, K. Wollenberg, M. Sellers et al., "An epigenetic antimalarial resistance mechanism involving parasite genes linked to nutrient uptake," Journal of Biological Chemistry, vol. 288, pp. 19429-19440, 2013.
[90] A. D. Pillai, W. Nguitragool, B. Lyko et al., "Solute restriction reveals an essential role for clag3-associated channels in malaria parasite nutrient acquisition," Molecular Pharmacology, vol. 82, pp. 1104-1114, 2012.

[91] S. Locovei, L. Bao, and G. Dahl, "Pannexin 1 in erythrocytes: function without a gap," Proceedings of the National Academy of Sciences of the United States of America, vol. 103, no. 20, pp. 7655-7659, 2006.

[92] W. Ma, V. Compan, W. Zheng et al., "Pannexin 1 forms an anion-selective channel," Pflugers Archiv European Journal of Physiology, vol. 463, pp. 585-592, 2012.

[93] J. M. Upston and A. M. Gero, "Increased glucose permeability in Babesia bovis-infected erythrocytes," International Journal for Parasitology, vol. 20, no. 1, pp. 69-76, 1990.

[94] K. Rönnebäumer, U. Gross, and W. Bohne, "The nascent parasitophorous vacuole membrane of Encephalitozoon cuniculi is formed by host cell lipids and contains pores which allow nutrient uptake," Eukaryotic Cell, vol. 7, no. 6, pp. 1001-1008, 2008.

[95] N. L. Hiller, S. Bhattacharjee, C. Van Ooij et al., "A host-targeting signal in virulence proteins reveals a secretome in malarial infection," Science, vol. 306, no. 5703, pp. 1934-1937, 2004.

[96] C. Hsiao, N. L. Hiller, K. Haldar, and L. J. Knoll, "A HT/PEXEL motif in toxoplasma dense granule proteins is a signal for protein cleavage but not export into the host cell," Traffic, vol. 14, pp. 519-531, 2013.

[97] T. F. De Koning-Ward, P. R. Gilson, J. A. Boddey et al., "A newly discovered protein export machine in malaria parasites," Nature, vol. 459, no. 7249, pp. 945-949, 2009.

[98] H. E. Bullen, S. C. Charnaud, M. Kalanon et al., "Biosynthesis, localization, and macromolecular arrangement of the Plasmodium falciparum translocon of exported proteins (PTEX)," Journal of Biological Chemistry, vol. 287, no. 11, pp. 7871-7884, 2012.

[99] D. T. Riglar, K. L. Rogers, E. Hanssen et al., "Spatial association with PTEX complexes defines regions for effector export into Plasmodium falciparum-infected erythrocytes," Nature Communications, vol. 4, article 1415, 2013.

[100] G. J. Leitch, M. Scanlon, A. Shaw, G. S. Visvesvara, and S. Wallace, "Use of a fluorescent probe to assess the activities of candidate agents against intracellular forms of Encephalitozoon microsporidia," Antimicrobial Agents and Chemotherapy, vol. 41, no. 2, pp. 337-344, 1997.

[101] S. A. Desai, D. J. Krogstad, and E. W. McCleskey, "A nutrientpermeable channel on the intraerythrocytic malaria parasite," Nature, vol. 362, no. 6421, pp. 643-646, 1993.

[102] S. A. Desai and R. L. Rosenberg, "Pore size of the malaria parasite's nutrient channel," Proceedings of the National Academy of Sciences of the United States of America, vol. 94, no. 5, pp. 20452049, 1997.

[103] J. C. Schwab, C. J. M. Beckers, and K. A. Joiner, "The parasitophorous vacuole membrane surrounding intracellular Toxoplasma gondii functions as a molecular sieve," Proceedings of the National Academy of Sciences of the United States of America, vol. 91, no. 2, pp. 509-513, 1994.

[104] J. A. Orellana, K. A. Schalper, V. Figueroa, H. A. Sánchez, and J. C. Sáez, "Regulation of intercellular calcium signaling through calcium interactions with connexin-based channels," Advances in Experimental Medicine and Biology, vol. 740, pp. 777-794, 2012.

[105] H. A. Sánchez, G. Meşe, M. Srinivas, T. W. White, and V. K. Verselis, "Differentially altered $\mathrm{Ca}^{2+}$ regulation and $\mathrm{Ca}^{2+}$ 
permeability in C x 26 hemichannels formed by the A40V and G45E mutations that cause keratitis ichthyosis deafness syndrome," Journal of General Physiology, vol. 136, no. 1, pp. 47$62,2010$.

[106] H. A. Sánchez, J. A. Orellana, V. K. Verselis, and J. C. Sáez, "Metabolic inhibition increases activity of connexin-32 hemichannels permeable to $\mathrm{Ca}^{2+}$ in transfected HeLa cells," American Journal of Physiology: Cell Physiology, vol. 297, no. 3, pp. C665-C678, 2009.

[107] K. A. Schalper, H. A. Sánchez, S. C. Lee, G. A. Altenberg, M. H. Nathanson, and J. C. Sáez, "Connexin 43 hemichannels mediate the $\mathrm{Ca}^{2+}$ influx induced by extracellular alkalinization," American Journal of Physiology: Cell Physiology, vol. 299, no. 6, pp. C1504-C1515, 2010.

[108] M. C. Fiori, V. Figueroa, M. E. Zoghbi, J. C. Sáez, and L. Reuss, "Permeation of calcium through purified Connexin 26 hemichannels," Journal of Biological Chemistry, vol. 287, pp. 40826-40834, 2012.

[109] S. N. J. Moreno, J. Silva, A. E. Vercesi, and R. Docampo, "Cytosolic-free calcium elevation in Trypanosoma cruzi is required for cell invasion," Journal of Experimental Medicine, vol. 180, no. 4, pp. 1535-1540, 1994.

[110] I. Tardieux, M. H. Nathanson, and N. W. Andrews, "Role in host cell invasion of Trypanosoma cruzi-induced cytosolic-free $\mathrm{Ca}^{2+}$ transients," Journal of Experimental Medicine, vol. 179, no. 3, pp. 1017-1022, 1994.

[111] N. N. Taniwaki, F. S. Machado, A. R. Massensini, and R. A. Mortara, "Trypanosoma cruzi disrupts myofibrillar organization and intracellular calcium levels in mouse neonatal cardiomyocytes," Cell and Tissue Research, vol. 324, no. 3, pp. 489-496, 2006.

[112] L. Li, X. Li, and J. Yan, "Alterations of concentrations of calcium and arachidonic acid and agglutinations of microfilaments in host cells during Toxoplasma gondii invasion," Veterinary Parasitology, vol. 157, no. 1-2, pp. 21-33, 2008.

[113] D. Soldati, B. J. Foth, and A. F. Cowman, "Molecular and functional aspects of parasite invasion," Trends in Parasitology, vol. 20, no. 12, pp. 567-574, 2004.

[114] J. Aliberti, J. G. Valenzuela, V. B. Carruthers et al., "Molecular mimicry of a CCR5 binding-domain in the microbial activation of dendritic cells," Nature Immunology, vol. 4, no. 5, pp. 485490, 2003.

[115] L. A. Caldas, W. de Souza, and M. Attias, "Calcium ionophoreinduced egress of Toxoplasma gondii shortly after host cell invasion," Veterinary Parasitology, vol. 147, no. 3-4, pp. 210-220, 2007.

[116] M. D. Lavine, L. J. Knoll, P. J. Rooney, and G. Arrizabalaga, "A Toxoplasma gondii mutant defective in responding to calcium fluxes shows reduced in vivo pathogenicity," Molecular and Biochemical Parasitology, vol. 155, no. 2, pp. 113-122, 2007.

[117] B. K. Davis, H. Wen, and J. P.-Y. Ting, "The Inflammasome NLRs in immunity, inflammation, and associated diseases," Annual Review of Immunology, vol. 29, pp. 707-735, 2011.

[118] L. Franchi, T. Eigenbrod, R. Muñoz-Planillo, and G. Nuñez, "The inflammasome: a caspase-1-activation platform that regulates immune responses and disease pathogenesis," Nature Immunology, vol. 10, no. 3, pp. 241-247, 2009.

[119] K. Schroder and J. Tschopp, “The Inflammasomes," Cell, vol. 140 , no. 6 , pp. 821-832, 2010.
[120] W. H. Witola, E. Mui, A. Hargrave et al., "NALP1 influences susceptibility to human congenital toxoplasmosis, proinflammatory cytokine response, and fate of Toxoplasma gondiiinfected monocytic cells," Infection and Immunity, vol. 79, no. 2, pp. 756-766, 2011.

[121] M. T. Shio, S. C. Eisenbarth, M. Savaria et al., "Malarial hemozoin activates the NLRP3 inflammasome through Lyn and Syk kinases," PLoS Pathogens, vol. 5, no. 8, Article ID e1000559, 2009.

[122] J. E. Contreras, H. A. Sánchez, E. A. Eugenín et al., "Metabolic inhibition induces opening of unapposed connexin 43 gap junction hemichannels and reduces gap junctional communication in cortical astrocytes in culture," Proceedings of the National Academy of Sciences of the United States of America, vol. 99, no. 1, pp. 495-500, 2002.

[123] R. J. Thompson, N. Zhou, and B. A. MacVicar, "Ischemia opens neuronal gap junction hemichannels," Science, vol. 312, no. 5775, pp. 924-927, 2006.

[124] M. C. Fernandes and N. W. Andrews, "Host cell invasion by Trypanosoma cruzi: a unique strategy that promotes persistence," FEMS Microbiology Reviews, vol. 36, no. 3, pp. 734-747, 2012.

[125] G. Ayna, D. V. Krysko, A. Kaczmarek, G. Petrovski, and P. Vandenabeele, "ATP release from dying autophagic cells and their phagocytosis are crucial for inflammasome activation in macrophages," PLoS ONE, vol. 7, Article ID e40069, 2012.

[126] R. Osawa, K. L. Williams, and N. Singh, "The inflammasome regulatory pathway and infections: role in pathophysiology and clinical implications," Journal of Infection, vol. 62, no. 2, pp. 119$129,2011$. 

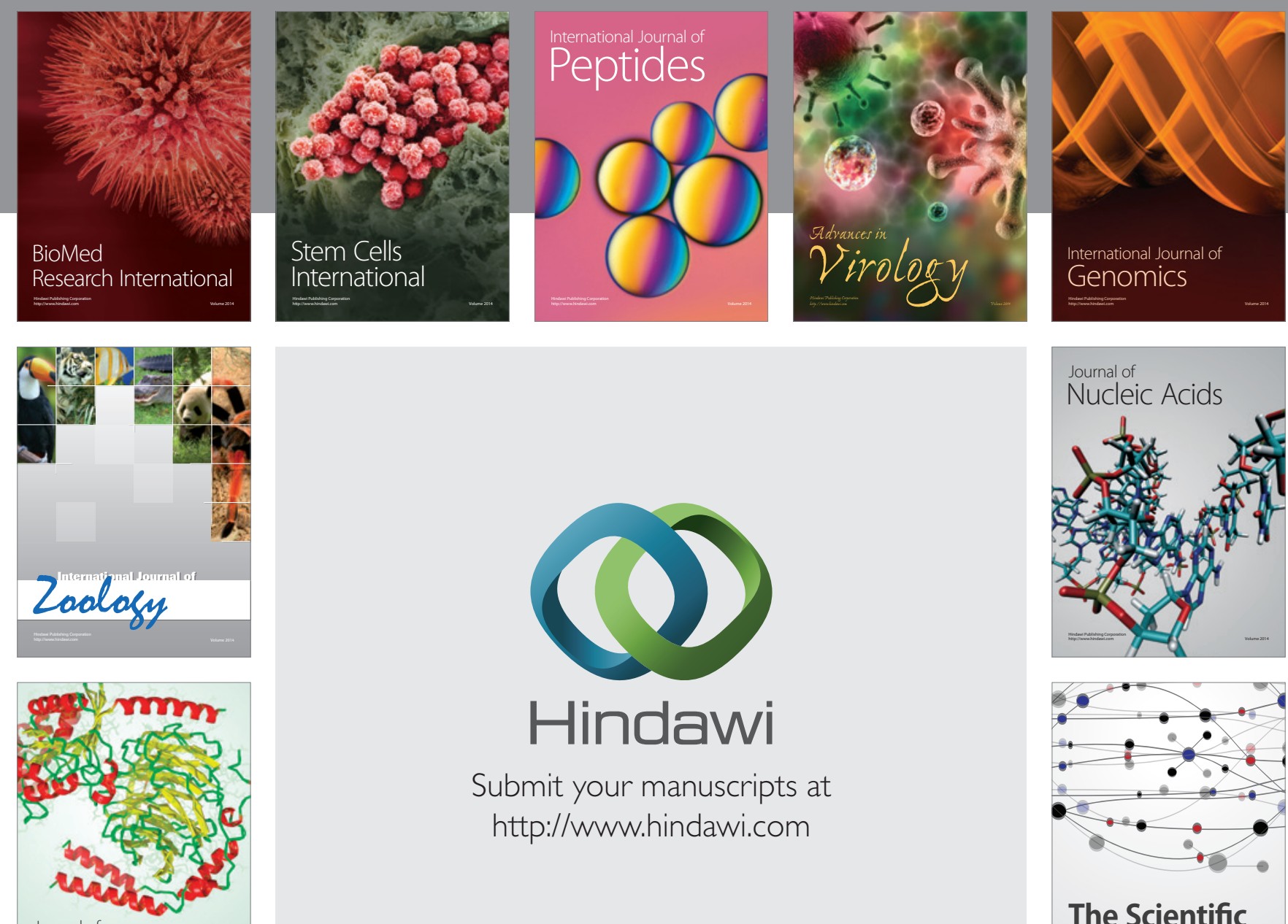

Submit your manuscripts at

http://www.hindawi.com

Journal of
Signal Transduction
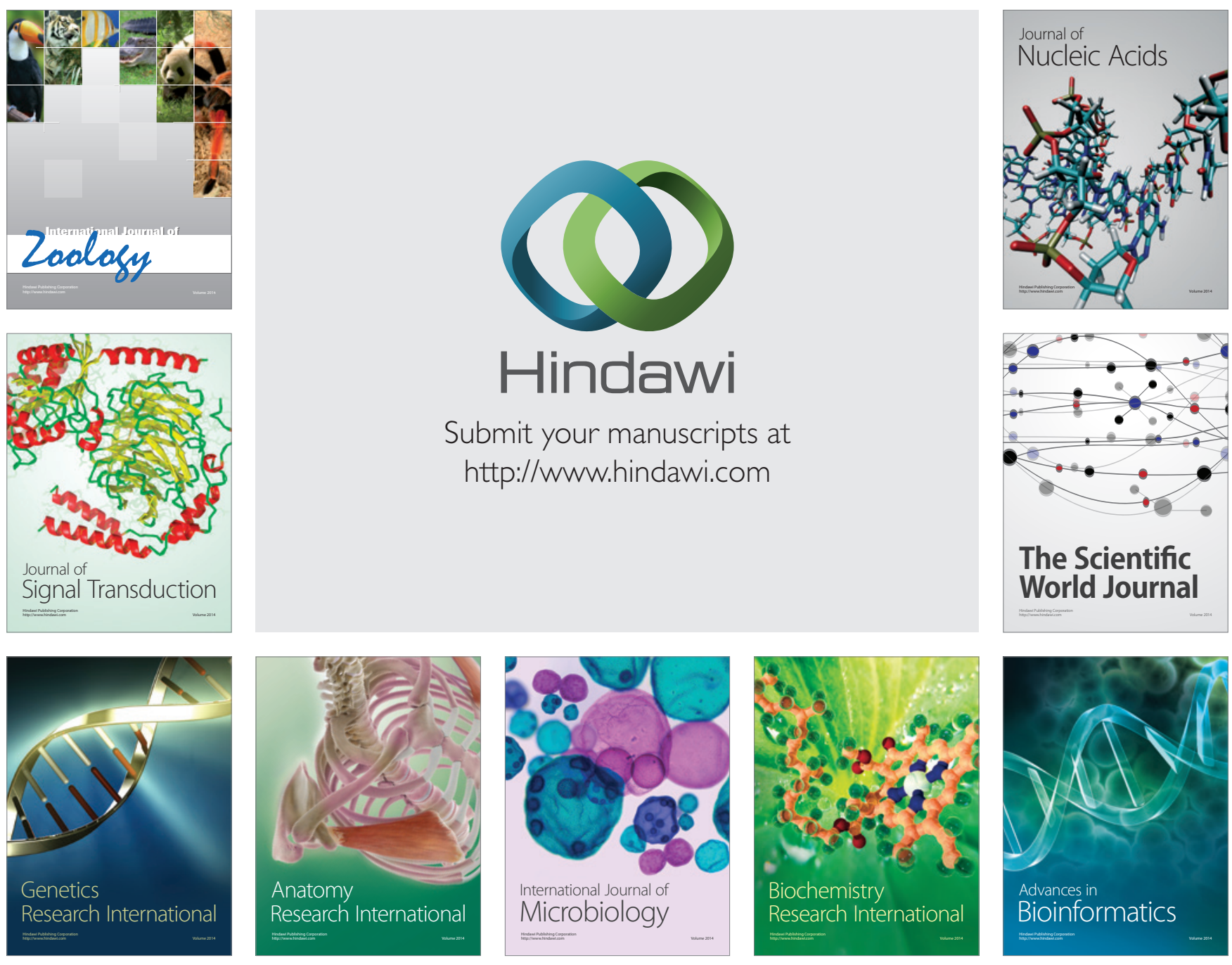

The Scientific World Journal
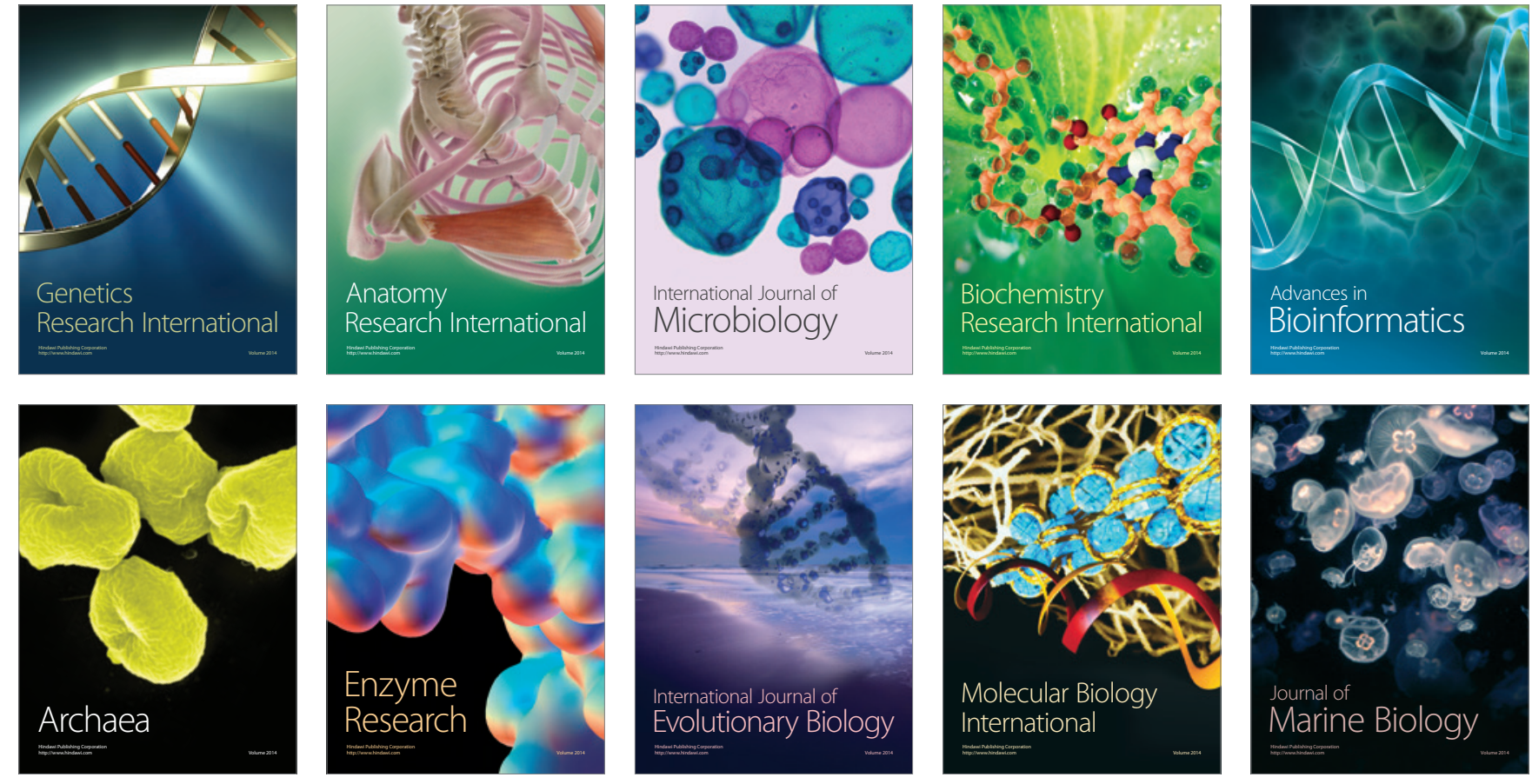